\title{
Evolutionary search for new compounds in the Ti-Si system
}

\section{D.O. Poletaev ${ }^{\text {a,* }}$, D.A. Aksyonov ${ }^{\text {b }}$, A.G. Lipnitskii ${ }^{\text {a }}$}

a The Center of Nanostructured Materials and Nanotechnologies, Belgorod State University, Belgorod, Russian Federation

b Skoltech Center for Energy Science and Technology, Skolkovo Institute of Science and Technology, 121205 Moscow, Russian Federation

\section{A R T I C L E I N F O}

\section{Keywords:}

$\mathrm{Ti}-\mathrm{Si}$

DFT

USPEX

Silicides

Predicted structures

\begin{abstract}
A B S T R A C T
In this work, the results of the evolutionary variable-composition search for binary compounds in the Ti-Si system are presented. The evolutionary algorithm did not find any new stable structures of silicides at $0 \mathrm{~K}$ and $0 \mathrm{GPa}$. On the other hand, many low-energy metastable and unstable structures are predicted. The 33 predicted and 10 known from literature but previously unstudied structures of compounds with low formation energies with respect to the ground-state line are analyzed. The mechanical properties, electronic band structures, densities of states, and temperature dependencies of thermodynamic stability of 17 dynamically stable previously unstudied structures are calculated.
\end{abstract}

\section{Introduction}

The Ti-Si system is an important subsystem for designing materials used in different technological applications. Titanium silicides play significant role in materials for microelectronic devices [1], corrosionresistant materials [2-5], materials for nuclear energy [6], and considered as promising materials for electrochemical energy storage $[7,8]$ and medicine $[9,10]$. Being intermetallic compounds, they exhibit useful combinations of properties such as high hardness, good corrosion resistance, and high melting temperature.

The equilibrium phase diagrams of the Ti-Si system [11-16] report about six stable titanium silicides, $\mathrm{Ti}_{3} \mathrm{Si}\left(\mathrm{P}_{2} / \mathrm{n} \mathrm{86}\right), \mathrm{Ti}_{5} \mathrm{Si}_{3}\left(\mathrm{P}_{3} / \mathrm{mcm}\right.$ 193), $\mathrm{Ti}_{5} \mathrm{Si}_{4}\left(\mathrm{P}_{1} 2_{1} 2\right.$ 92), TiSi (Pnma 62), $\mathrm{TiSi}_{2}$ (Fddd 70), and $\mathrm{TiSi}_{2}$ (Cmcm 63), that were observed in experimental works [17-36]. However, there are several reasons to suppose that not all possible structures of titanium silicides are covered by existing equilibrium phase diagrams of the Ti-Si system.

Firstly, in the experimental investigations, only limited concentration and temperature ranges of phase equilibria were considered. For example, in the works devoted to investigations of silicide precipitation in titanium alloys, the studied concentration ranges were limited to a few atomic percent [17,18,23,28,31,33,34,36-48]. In the works, devoted to determining phase equilibria and construction of phase diagrams $[28,39,48-53]$, the temperature ranges were limited by temperatures sufficiently high (above $600 \mathrm{~K}$ ) for complete equilibration.

Secondly, the information from existing equilibrium phase diagrams is often used for interpretation of experimental results which lowers the probability of discovering new silicides. For example, in the works devoted to synthesis of titanium silicides [20,54], the stoichiometric ratios of precursors were selected based on the information from the existing equilibrium phase diagrams. Moreover, in some experimental works $[31,33]$ the structures of silicides were deduced either from the Si content in the phases [31] or solely from the equilibrium phase diagrams [33] rather than determined with the required techniques such as electron or X-ray diffraction. Thus, there is a probability that there could be other structures of titanium silicides that were not yet observed experimentally for one of the reasons highlighted above.

The growing power of computational approaches allowing to make fully theoretical crystal structure predictions using global optimization methods based on $a b$ initio calculations lays out the way to overcome the difficulties of experimental approaches in the task of discovering new compounds. There are successful examples of $a b$ initio based predictions of new stable structures even in the well-studied systems that were confirmed by experiments [55]. For example, the structure of $\mathrm{MnB}_{3}$ in the $\mathrm{Mn}-\mathrm{B}$ system with this stoichiometric ratio was never experimentally observed until the theoretical predictions of its stability were made [55].

In the $\mathrm{Ti}-\mathrm{Si}$ system, the theoretical crystal structure predictions were made only for 2D systems [56] using particle-swarm optimization with the CALYPSO package [57]. For 3D systems, only the DFT calculations of formation energies were carried out for structures that are stable in chemically similar systems of early transition metals or rare earths with p-elements [58-62]. However, there were no attempts to find completely new stable structures of 3D titanium silicides in the Ti-Si system.

In this work, we make such an attempt by doing the global variablecomposition search for 3D structures of titanium silicides in the Ti-Si

\footnotetext{
* Corresponding author.

E-mail address: poletaev.dan@gmail.com (D.O. Poletaev).
} 
system at $0 \mathrm{~K}$ and $0 \mathrm{GPa}$ using the evolutionary algorithm USPEX [63$66]$.

\section{Details of calculations}

The global search for new compounds in the binary Ti-Si system was conducted using evolutionary algorithm USPEX [63-66] on the basis of DFT calculated total energies with the VASP code $[67,68]$. To cover all possible compositions we used the variable-composition feature $[69,70]$ of the USPEX code. Since in the variable-composition search minimal and maximal numbers of atoms in a structure should not differ by more than two times, we performed four global searches of compounds with structures containing 2-4, 4-8, 8-16, and 16-32 atoms per unit cell. The minimum number of atoms (2) correspond to the number of atoms in the unit cell of $\alpha$-Ti hexagonal close-packed structure, while the maximum number of atoms (32) correspond to the number of atoms in the unit cell of $\mathrm{Ti}_{3} \mathrm{Si}\left(\mathrm{P}_{2} / \mathrm{n} \mathrm{86}\right)$ structure from experimental phase diagrams. We did not consider structures with larger number atoms in a unit cell as only ordered solid solution structures are expected there. The evolutionary searches for compounds in these subsystems were started from 165, 165, 165, and 70 random structures, respectively, distributed among 11 random compositions from pure $\mathrm{Ti}$ to pure Si. Further generations of structures consisted of $120,120,120$, and 70 individuals (in subsystems with 2-4, 4-8, 816 , and 16-32 atoms per unit cell, respectively) were produced by the combination of heredity (40\%), random generation from space groups (10\%), random topology [71] (10\% in $8-16$ atoms subsystem, $0 \%$ in other), soft mutation (20\%) and transmutation (20\%) of atoms. The searches were stopped if the most stable found structures did not change for 20 generations, that was done when 77, 89, 35, and 27 generations of structures were treated in subsystems with 2-4, 4-8, 8-16, and 16-32 atoms per unit cell, respectively.

To increase the probability of finding completely new structures, the searches for compounds in 2-4, 4-8, and 8-16 subsystems were conducted without any preliminary information about already known structures (i.e. no seed structures were used). However, the search for compounds in the 16-32 subsystem was conducted using known phase diagram structures of silicides and pure elements, which were considered in our previous work [72]. Three unary structures of $\alpha$ Ti (P6 6 /mmc 194), $\omega$-Ti (P6/mmm 191), and diamond Si (Fd $3 \bar{m}$ 227) were added as seeds to the 4 th generation, while the seven binary structures, $\mathrm{Ti}_{5} \mathrm{Si}_{3}\left(\mathrm{P}_{3} / \mathrm{mcm} \mathrm{193}\right.$ ), $\mathrm{Ti}_{5} \mathrm{Si}_{4}$ ( $\left(\mathrm{P}_{1} 2_{1} 2\right.$ 92), TiSi (Pnma 62), $\mathrm{TiSi}_{2}$ (Cmcm 63), $\mathrm{Ti}_{3} \mathrm{Si}\left(\mathrm{P} 4_{2} / \mathrm{n} \mathrm{86}\right.$ ), $\mathrm{Ti}_{2} \mathrm{Si}\left(\mathrm{P} 4_{2} / \mathrm{n} \mathrm{189}\right.$ ), and $\mathrm{TiSi}_{2}$ (Fddd 70 ), were added as seeds to the 20th generation. The latter allows to prevent focusing the search on disordered low-symmetry structures the number of which increases exponentially with the system size and fills the energy landscape with local minima [73,74]. The crystallographic information with formation energies of binary seed structures in comparison with available experimental and calculated data are collected in Table 1. Formation energies, $E_{f}$, of $\mathrm{Ti}_{x} \mathrm{Si}_{y}$ structures were calculated as follows:

$E_{f}=E_{0}^{\mathrm{Ti}_{x} \mathrm{Si}_{y}}-x E_{0}^{\mathrm{Ti}}-x E_{0}^{\mathrm{Si}}$,

where $E_{0}^{\mathrm{Ti}_{x} \mathrm{Si}_{y}}, E_{0}^{\mathrm{Ti}}$, and $E_{0}^{\mathrm{Si}}$ are DFT total energies per atom of a $\mathrm{Ti}_{x} \mathrm{Si}_{y}$ structure, and structures of $\alpha$-Ti and diamond Si, respectively.

The relaxation of generated by USPEX structures and calculation of their energies were done within the density functional theory (DFT) using generalized gradient approximation (GGA) with Perdew-BurkeErnzerhof parametrization [79] and projector-augmented wave (PAW) [80] potentials as implemented in VASP [68]. There were four steps for structure relaxation and one additional step for the precise calculation of structure energy. We used PAW potentials with $3 s^{2} 3 \mathrm{p}^{6} 3 \mathrm{~d}^{2} 4 \mathrm{~s}^{2}$ valence electrons for $\mathrm{Ti}$ and with $3 \mathrm{~s}^{2} 3 \mathrm{p}^{2}$ valence electrons for $\mathrm{Si}$. The calculation parameters with these PAW potentials such as energy cutoff (ENCUT) and density of k-points (KSPACING) were tested in our previous work [72]. In this study, we use slightly increased energy
Table 1

Compositions (Comp.), symmetries (Spg. and No.), Pearson symbols, prototypes, formation energies $\left(E_{f}\right)$, and distances to the ground-state line (Stability) of the binary seed structures in comparison with experimental data at high temperatures [75,76], DFT data at $0 \mathrm{~K}[58]$, and CALPHAD data at $298 \mathrm{~K}[13,77]$.

\begin{tabular}{|c|c|c|c|c|c|c|}
\hline Comp. & Spg. & No. & $\begin{array}{l}\text { Pearson } \\
\text { symbol }\end{array}$ & Prot. & $\begin{array}{l}E_{f} \\
\text { eV/atom }\end{array}$ & $\begin{array}{l}\text { Stability, } \\
\text { eV/atom }\end{array}$ \\
\hline $\mathrm{Ti}_{3} \mathrm{Si}$ & $\mathrm{P} 4_{2} / \mathrm{n}$ & 86 & tP32 & $\mathrm{Ti}_{3} \mathrm{P}$ & $\begin{array}{l}-0.499 \text { (this work) } \\
-0.488[58] \\
-0.518[13,77,78]\end{array}$ & $\begin{array}{l}0.014 \\
0.013\end{array}$ \\
\hline $\mathrm{Ti}_{2} \mathrm{Si}$ & $\bar{P} \overline{6} 2 \mathrm{~m}$ & 189 & hP9 & $\mathrm{Fe}_{2} \mathrm{P}$ & $\begin{array}{l}-0.682 \text { (this work) } \\
-0.670[58]\end{array}$ & $\begin{array}{l}0.002 \\
0.000\end{array}$ \\
\hline $\mathrm{Ti}_{5} \mathrm{Si}_{3}$ & $\mathrm{P}_{3} / \mathrm{mcm}$ & 193 & hP16 & $\mathrm{Mn}_{5} \mathrm{Si}_{3}$ & $\begin{array}{l}-0.770 \text { (this work) } \\
-0.752[58] \\
-0.809 \pm 0.052[75] \\
-0.765 \pm 0.021[76] \\
-0.756[13,77,78]\end{array}$ & $\begin{array}{l}0.000 \\
0.000\end{array}$ \\
\hline $\mathrm{Ti}_{5} \mathrm{Si}_{4}$ & $\mathrm{P} 4_{1} 2_{1} 2$ & 92 & tP36 & $\mathrm{Zr}_{5} \mathrm{Si}_{4}$ & $\begin{array}{l}-0.791 \text { (this work) } \\
-0.773[58] \\
-0.786 \pm 0.052[75] \\
-0.814 \pm 0.022[76] \\
-0.819[13,77,78]\end{array}$ & $\begin{array}{l}0.000 \\
0.000\end{array}$ \\
\hline TiSi & Pnma & 62 & oP8 & $\mathrm{FeB}$ & $\begin{array}{l}-0.770 \text { (this work) } \\
-0.749[58] \\
-0.741 \pm 0.052[75] \\
-0.752 \pm 0.020[76] \\
-0.804[13,77,78]\end{array}$ & $\begin{array}{l}0.000 \\
0.000\end{array}$ \\
\hline $\mathrm{TiSi}_{2}$ & $\mathrm{Cmcm}$ & 63 & oC12 & $\mathrm{ZrSi}_{2}$ & $\begin{array}{l}-0.562 \text { (this work) } \\
-0.532[58]\end{array}$ & $\begin{array}{l}0.000 \\
0.000\end{array}$ \\
\hline $\mathrm{TiSi}_{2}$ & Fddd & 70 & oF 24 & $\mathrm{TiSi}_{2}$ & $\begin{array}{l}-0.555 \text { (this work) } \\
-0.517[58] \\
-0.554 \pm 0.052[75] \\
-0.591 \pm 0.029[76] \\
-0.605[13,77,78]\end{array}$ & $\begin{array}{l}0.007 \\
0.015\end{array}$ \\
\hline
\end{tabular}

cutoff $(500 \mathrm{eV})$ on the two final steps. The density of k-points increased from step to step. At the first step (crude relaxation), the maximum distance between two k-points in reciprocal space was equal to 0.25 $2 \pi / \AA$, while at the last step (precise energy calculation) it was equal to $0.052 \pi / \AA$. For all relaxation steps we used the $0.2 \mathrm{eV}$ MethfesselPaxton [81] smearing of the Fermi level while for the step of precise calculation the smearing width was reduced to $0.06 \mathrm{eV}$.

As it is seen from Table 1 the calculation setup allows to reproduce the formation energies of known structures used as seeds in a fair agreement with experimental [75,76], CALPHAD [13,77] and DFT values of other authors [58]. The maximum deviation of calculated formation enthalpies from experimental values is within $9 \%$ for $\mathrm{TiSi}_{2}$ (Fddd 70) structure.

After the search, a number of selected structures were additionally analyzed with the help of SIMAN high-throughput software for DFT calculations [82].

Firstly, the repeating structures were removed from the results of different searches. The repeatability of structures was assessed on the basis of their topological similarity. As a measure of structure similarity, we used an Euclidean distance between 61-dimensional structure fingerprint vectors proposed by Zimmermann et al. [83] and implemented in the matminer python package:

$d=\left\|\mathrm{v}_{i}-\mathrm{v}_{j}\right\|=\sqrt{\sum_{k=1}^{N_{d i m}}\left(v_{i}^{k}-v_{j}^{k}\right)^{2}}$,

where $\mathrm{v}_{i}$ and $\mathrm{v}_{j}$ are the fingerprint vectors of structures $i$ and $j, v_{i}^{k}$ and $v_{j}^{k}$ are the components of these vectors in the $N_{\text {dim }}=61$ dimensional space. Each component of the structure fingerprint vector contains information about the mean value, its standard deviation, minimum, and maximum values of the likelihood of the structure sites to be one of the 61 coordination motifs, described in the original article [83]. This technique is used in the Materials project database for finding 
similar structures for a given structure in other systems, where the structures are considered similar if the Euclidean distance between their fingerprint vectors is less than 0.75 . In our work, the structures were considered similar and marked as repeating if the Euclidean distance between their fingerprint vectors was less than 0.7 , and if they had the same stoichiometry.

To ensure that selected unique structures have equilibrium volumes and relaxed positions of atoms, a series of constant volume calculations and atomic relaxations were additionally performed in VASP [67]. The phonon properties of additionally relaxed structures were calculated using supercell approach with the help of the Phonopy code [84]. The forces in the relaxed unit cells before constructing supercells for phonon calculations were less than $0.001 \mathrm{eV} / \AA$. To calculate the forces in supercells, we used the displacement distance of $0.05 \AA$. The elastic constants, electronic band structures and densities of states of dynamically stable structures, were calculated in VASP [67]. For calculations of the elastic constants we used the conventional unit cells of structures in which positions of atoms were relaxed until forces acting on them become less than $0.001 \mathrm{eV} / \AA$. To ensure that we can rely on the calculated elastic constants for predicted structures, we have tested the calculation parameters on structures of $\alpha$-Ti $\left(\mathrm{P}_{3} / \mathrm{mmc} 194\right)$, diamond $\mathrm{Si}(\mathrm{Fd} \overline{3} \mathrm{~m}$ 227), and $\mathrm{Ti}_{5} \mathrm{Si}_{3}\left(\mathrm{P}_{3} / \mathrm{mcm}\right.$ 193) for which the experimental data is known; see Refs. [85,86], and [87], respectively.

The agreement with experimental values is satisfactory. The maximum deviations from experimental data in absolute values of elastic constants are 12.1 GPa for diamond $\mathrm{Si}(\mathrm{Fd} \overline{3} \mathrm{~m} \mathrm{227)}, 15.5 \mathrm{GPa}$ for $\alpha$ $\mathrm{Ti}\left(\mathrm{P}_{3} / \mathrm{mmc} 194\right)$, and $12.7 \mathrm{GPa}$ for $\mathrm{Ti}_{5} \mathrm{Si}_{3}\left(\mathrm{P}_{3} / \mathrm{mcm} \mathrm{193}\right)$, which correspond to relative deviations of $14 \%, 12 \%$, and $24 \%$, respectively; see Table 2 .

\section{Results and discussion}

\subsection{The results of the global structure search}

During the evolutionary variable composition searches for compounds in the Ti-Si system at $0 \mathrm{~K}$ and $0 \mathrm{GPa}, 869,1929,1761$, and 915 structures were found in the subsystems with 2-4, 4-8, 8-16, and 16-32 atoms per unit cell, respectively. After filtering repeating structures on the basis of their fingerprints, this has resulted in 1601 unique binary structures and 161 unique unary structures. In the searches within the subsystems containing 2-4, 4-8 and 8-16 atoms per unit cell, where no seed structures were used, the evolutionary algorithm successfully found unary structures of $\alpha$-Ti (P6 $\left.6_{3} / \mathrm{mmc} 194\right), \omega$-Ti (P6/mmm 191), and diamond $\mathrm{Si}(\mathrm{Fd} \overline{3} \mathrm{~m} 227)$, as well as binary structures of TiSi (Pnma 62), $\mathrm{TiSi}_{2}$ (Cmcm 63), and $\mathrm{TiSi}_{2}$ (Fddd 70) silicides known from equilibrium phase diagrams [11-16]. The structures of other equilibrium silicides, $\mathrm{Ti}_{5} \mathrm{Si}_{3}\left(\mathrm{P}_{3} / \mathrm{mcm} \mathrm{193}\right), \mathrm{Ti}_{3} \mathrm{Si}\left(\mathrm{P} 4_{2} / \mathrm{n} 86\right)$, and $\mathrm{Ti}_{5} \mathrm{Si}_{4}\left(\mathrm{P}_{1} 2_{1} 2\right.$ 92) were not found by the evolutionary algorithm within these subsystems, because unit cells of these structures consist of larger numbers of atoms. When searching in a subsystem containing 16-32 atoms per unit cell, the structures of known silicides were used as seeds, and we cannot say whether they would have been found by the evolutionary algorithm without preliminary information about them.

In Fig. 1, a convex hull diagram of the Ti-Si system containing formation energies of the predicted structures with respect to the hexagonal close-packed (hcp) $\alpha$-Ti and cubic diamond $\mathrm{Si}$ at $0 \mathrm{~K}$ and $0 \mathrm{GPa}$ is shown. The structures of binary silicides that were used as seeds during the evolutionary search in the subsystem with 16-32 atoms per unit cell are annotated. It is seen, that the evolutionary algorithm did not found any new stable structures of silicides at $0 \mathrm{~K}$ and $0 \mathrm{GPa}$. On the other hand, many low-energy metastable (or unstable) structures were predicted. However, because the number of predicted binary structures is too large, we selected the most interesting ones for more detailed analysis.

In this study, firstly, we considered all binary structures with the formation energies not higher than $50 \mathrm{meV}$ above the ground-state

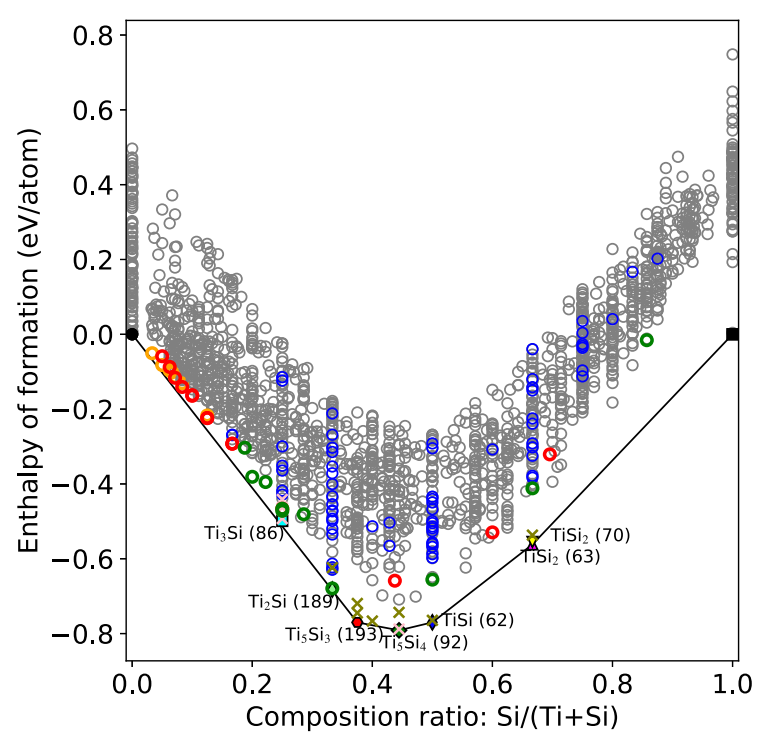

Fig. 1. The convex hull diagram of the Ti-Si system with respect to hexagonal close-packed $\alpha$-Ti and cubic diamond Si at $0 \mathrm{~K}$ and $0 \mathrm{GPa}$. The structures of binary silicides that were used as seeds in the evolutionary search are annotated. Blue circles denote the structures that have the same stoichiometry and topologically close to the structures stored in the Materialsproject [59], Open Quantum Materials [60,61], and AFLOWlib [62,90] databases. Orange circles denote the hcp superstructures ("solid solution" structures), red circles denote the dynamically unstable structures, while the green circles denote the dynamically stable structures that were selected for more detailed analysis. Gray circles denote other predicted structures that were not considered in this work. Crosses denote the low-energy structures from the article of Colinet et al. [58] and structures stored in Materialsproject [59], Open Quantum Materials [60,61], and AFLOWlib [62,90] databases that were considered in this work in addition to the predicted low-energy structures: pink crosses denote the dynamically unstable structures, while olive crosses denote the dynamically stable structures.

line on the convex hull diagram because they are the primary candidates that could be thermodynamically stabilized at temperatures not higher than the melting temperature $(50 \mathrm{meV}$ corresponds to $\approx$ $600 \mathrm{~K}$ ) and become the part of the equilibrium phase diagrams. These structures also can be very useful in the fitting and validation of the semiempirical or machine-learning interatomic potentials for the TiSi system. Detailed sampling of the potential energy surface near the global minima improves the transferability of the potentials preventing situations when some local minimum structure is incorrectly predicted as the global minimum structure.

There are 23 metastable or unstable structures of silicides with formation energies not higher than $50 \mathrm{meV}$ above the convex hull, and all of them are in the Ti-rich region. Among them, there are ten triclinic structures, namely, $\mathrm{Ti}_{29} \mathrm{Si}$ (P1 1), two $\mathrm{Ti}_{15} \mathrm{Si}$ (P1 1), $\mathrm{Ti}_{14} \mathrm{Si}$ (P1 1), $\mathrm{Ti}_{11} \mathrm{Si}$ (P1 1), $\mathrm{Ti}_{9} \mathrm{Si}\left(\mathrm{P} 1\right.$ 1), $\mathrm{Ti}_{7} \mathrm{Si}(\mathrm{P} \overline{1} 2), \mathrm{Ti}_{5} \mathrm{Si}(\mathrm{P} \overline{1} 2), \mathrm{Ti}_{4} \mathrm{Si}\left(\mathrm{P} 1\right.$ 2), and $\mathrm{Ti}_{3} \mathrm{Si}(\mathrm{P} 1$ 1); six monoclinic structures, namely, two $\mathrm{Ti}_{19} \mathrm{Si}\left(\mathrm{Pm} \mathrm{6}\right.$ ), $\mathrm{Ti}_{13} \mathrm{Si}$ (C2 5), $\mathrm{Ti}_{11} \mathrm{Si}(\mathrm{C} 25), \mathrm{Ti}_{9} \mathrm{Si}\left(\mathrm{P} 2_{1} / \mathrm{m} \mathrm{11}\right)$, and $\mathrm{Ti}_{7} \mathrm{Si}\left(\mathrm{P} 2_{1} / \mathrm{m} \mathrm{11}\right)$; five orthorhombic structures, namely, $\mathrm{Ti}_{15} \mathrm{Si}$ (Fmm2 42), $\mathrm{Ti}_{13} \mathrm{Si}\left(\mathrm{Amm} 2\right.$ 38), $\mathrm{Ti}_{7} \mathrm{Si}$ (Pmmn 59), $\mathrm{Ti}_{3} \mathrm{Si}\left(\mathrm{Cmcm} \mathrm{63)}\right.$ and $\mathrm{Ti}_{3} \mathrm{Si}$ (Cmcm 63) of $\mathrm{Cd}_{3} \mathrm{Y}$-prototype; one tetragonal structure, namely, $\mathrm{Ti}_{2} \mathrm{Si}\left(\mathrm{I} 4 / \mathrm{mcm} \mathrm{140)}\right.$ of $\mathrm{Al}_{2} \mathrm{Cu}$-prototype, and one trigonal structure, namely, $\mathrm{Ti}_{5} \mathrm{Si}$ ( $\mathrm{R} 32$ 155).

Secondly, to cover the equiatomic and Si-rich compositions, we considered high-symmetry binary structures with formation energies higher than $50 \mathrm{meV}$ above the convex hull but minimal with respect to the ground-state line at a given stoichiometric ratio. Among them, there are three tetragonal structures, TiSi ( $\overline{\mathrm{P}} \overline{\mathrm{m}} 2$ 115), $\mathrm{Ti}_{13} \mathrm{Si}_{3}(\mathrm{P} 4 / \mathrm{mmm}$ 123) and $\mathrm{Ti}_{7} \mathrm{Si}_{16}$ (P4/mmm 123); two orthorhombic structures, $\mathrm{Ti}_{2} \mathrm{Si}_{3}$ (Immm 71) and $\mathrm{Ti}_{7} \mathrm{Si}_{2}$ (Fmmm 69); three trigonal structures, $\mathrm{Ti}_{9} \mathrm{Si}_{7}$ (P312 149), $\mathrm{Ti}_{5} \mathrm{Si}_{2}$ ( $\left.\mathrm{R} \overline{3} \mathrm{~m} 166\right)$ and $\mathrm{TiSi}_{2}$ ( $\mathrm{R} \overline{3} \mathrm{~m} \mathrm{166}$ ); and one hexagonal structure, $\mathrm{TiSi}_{6}$ (P6/mmm 191).

In Table 3 the compositions, space groups, Pearson symbols, prototypes, formation energies, and stabilities (energies above the convex 
Table 2

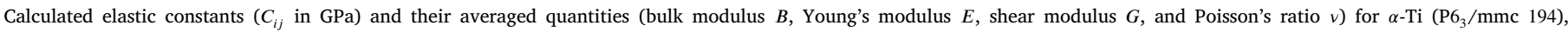

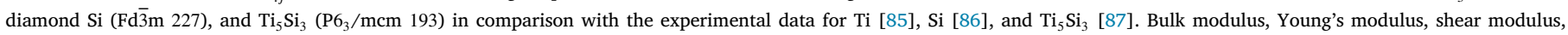
Poisson's ratio were obtained by averaging of elastic constants using Voigt-Reuss-Hill [88] scheme as implemented in the ELATE web-application [89].

\begin{tabular}{|c|c|c|c|c|c|c|c|c|c|c|c|c|}
\hline & \multicolumn{4}{|c|}{$\alpha$-Ti $\left(\mathrm{P6}_{3} / \mathrm{mmc} 194\right)$} & \multicolumn{4}{|c|}{ diamond $\mathrm{Si}(\mathrm{Fd} \overline{3} \mathrm{~m}$ 227) } & \multicolumn{4}{|c|}{$\mathrm{Ti}_{5} \mathrm{Si}_{3}\left(\mathrm{P}_{3} / \mathrm{mcm} \mathrm{193}\right)$} \\
\hline & Our & Exp. & $\Delta, \mathrm{GPa}$ & $\Delta, \%$ & Our & Exp. & $\Delta, \mathrm{GPa}$ & $\Delta, \%$ & Our & Exp. & $\Delta, \mathrm{GPa}$ & $\Delta, \%$ \\
\hline$C_{11}$ & 174.8 & 176.1 & -1.3 & $-1 \%$ & 152.0 & 167.5 & -15.5 & $-9 \%$ & 282.4 & 285.0 & -2.6 & $-1 \%$ \\
\hline$C_{22}$ & 174.8 & 176.1 & -1.3 & $-1 \%$ & 152.0 & 167.5 & -15.5 & $-9 \%$ & 282.4 & 285.0 & -2.6 & $-1 \%$ \\
\hline$C_{33}$ & 195.1 & 190.5 & 4.6 & $2 \%$ & 152.0 & 167.5 & -15.5 & $-9 \%$ & 258.5 & 268.0 & -9.5 & $-4 \%$ \\
\hline$C_{44}$ & 50.0 & 50.8 & -0.8 & $-2 \%$ & 73.9 & 80.2 & -6.4 & $-8 \%$ & 92.7 & 93.0 & -0.3 & $-0.3 \%$ \\
\hline$C_{55}$ & 49.2 & 50.8 & -1.6 & $-3 \%$ & 73.9 & 80.2 & -6.4 & $-8 \%$ & 91.0 & 93.0 & -2.0 & $-2 \%$ \\
\hline$C_{66}$ & 49.2 & 44.6 & 4.6 & $10 \%$ & 73.9 & 80.2 & -6.4 & $-8 \%$ & 91.0 & 89.3 & 1.7 & $2 \%$ \\
\hline$C_{12}$ & 74.8 & 86.9 & -12.1 & $-14 \%$ & 56.9 & 64.9 & -8.0 & $-12 \%$ & 96.9 & 106.0 & -9.1 & $-9 \%$ \\
\hline$C_{13}$ & 71.7 & 68.3 & 3.4 & $5 \%$ & 56.9 & 64.9 & -8.0 & $-12 \%$ & 40.7 & 53.4 & -12.7 & $-24 \%$ \\
\hline$C_{23}$ & 71.7 & 68.3 & 3.4 & $5 \%$ & 56.9 & 64.9 & -8.0 & $-12 \%$ & 40.7 & 53.4 & -12.7 & $-24 \%$ \\
\hline$B$ & 108.9 & 110.0 & -1.1 & $-1 \%$ & 88.6 & 99.1 & -10.5 & $-11 \%$ & 130.1 & 139.6 & -9.5 & $-7 \%$ \\
\hline$E$ & 133.1 & 130.6 & 2.5 & $2 \%$ & 150.7 & 166.3 & -15.6 & $-9 \%$ & 233.4 & 234.5 & -1.1 & $-0.5 \%$ \\
\hline$G$ & 51.3 & 50.2 & 1.1 & $2 \%$ & 61.9 & 67.1 & -5.2 & $-8 \%$ & 97.2 & 96.1 & 1.1 & $1 \%$ \\
\hline$v$ & 0.296 & 0.302 & -0.006 & $-2 \%$ & 0.217 & 0.224 & -0.007 & $-3 \%$ & 0.201 & 0.220 & -0.019 & $-9 \%$ \\
\hline$G / B$ & 0.471 & 0.457 & 0.015 & $3 \%$ & 0.699 & 0.677 & 0.022 & $3 \%$ & 0.747 & 0.688 & 0.058 & $8 \%$ \\
\hline$B / G$ & 2.122 & 2.191 & -0.069 & $-3 \%$ & 1.431 & 1.477 & -0.047 & $-3 \%$ & 1.339 & 1.453 & -0.113 & $-8 \%$ \\
\hline
\end{tabular}

hull) of the selected 32 structures are presented in the ascending order of the Si fraction. These structures are highlighted by orange, red, and green circles on the convex hull diagram (the meaning of the colors will be explained further).

The information about translation vectors and atomic coordinates of these structures in the POSCAR format and detailed text descriptions of structures prepared by robocrystallographer [91] are provided in the Supplementary Materials.

From Table 3, it can be seen that eight Ti-rich structures have the P1 or $\mathrm{P} \overline{1}$ space group. Other eight structures have the $\mathrm{C} 2, \mathrm{Pm} 6$, or $\mathrm{P} 2_{1} / \mathrm{m}$ space group. One of the ways to obtain low symmetry structures is to introduce point defects in high symmetry structures. Since the USPEX used the operations of soft mutation and transmutation of atoms during the global search, the part of the predicted structures should contain point defects.

Because these low-energy predicted structures are found in the Tirich region, it is natural to suppose that part of them can be ordered superstructures representing substitutional solid solutions of $\mathrm{Si}$ in $\mathrm{Ti}$ with one of the two experimentally known lattices having the lowest enthalpies at $0 \mathrm{~K}$ : hexagonal close-packed (hcp), named $\alpha$-Ti and $\omega$-Ti. In substitutional solid solutions the local environments of each atom should be the same as in the pure structures of the host element. Given this, the criterion that we can use to classify structures as ordered superstructures representing substitutional solid solutions of Si in $\alpha$ $\mathrm{Ti}$ or $\omega$-Ti is their topological similarity to the structures of pure $\alpha$-Ti and $\omega$-Ti. As a measure of topological similarity it is convenient to use the already adopted in this work Euclidean distance between 61dimensional fingerprint vectors, Eq. (2), of predicted Ti-rich structures, and structures of $\alpha$-Ti and $\omega$-Ti disregarding the differences in their chemical compositions.

It was found that the condition of structure similarity assumed in our work (Euclidean distance between structure fingerprint vectors less than 0.7) is valid for the hcp structure of $\alpha$-Ti, and eight lowenergy Ti-rich structures with $\mathrm{Si}$ fraction from 0.03 to 0.125 , namely $\mathrm{Ti}_{29} \mathrm{Si}$ (P1 1), Ti ${ }_{19} \mathrm{Si}$ (Pm 6), $\mathrm{Ti}_{15} \mathrm{Si}$ (P1 1), $\mathrm{Ti}_{15} \mathrm{Si}$ (Fmm2 42), $\mathrm{Ti}_{14} \mathrm{Si}$ (P1 1), $\mathrm{Ti}_{13} \mathrm{Si}$ (Amm2 38), $\mathrm{Ti}_{11} \mathrm{Si}$ (P1 1), and $\mathrm{Ti}_{7} \mathrm{Si}$ (Pmmn 59). These structures are listed in the orange rows in Table 3. Note, that among these eight structures, there are four triclinic, one monoclinic, and three orthorhombic structures, i.e. not only low-symmetry triclinic and monoclinic structures as it was supposed before. None of the predicted structures were found to be topologically similar to the structure of $\omega$-Ti as the Euclidean distances between their fingerprint vectors are more than 1.2

Due to the local nature of the fingerprint method [83], these eight structures with fingerprint vector close to $\alpha$-Ti should have similar local atomic environments with the $\alpha$-Ti. In pure $\alpha$-Ti, each Ti atom is surrounded by $12 \mathrm{Ti}$ atoms forming a mixture of the corner, face, and edge-sharing $\mathrm{Ti}-\mathrm{Ti}_{12}$ cuboctahedra. There are six shorter $(2.88 \AA)$ and six longer $(2.94 \AA)$ Ti-Ti bonds between central Ti atom and 12 surrounding Ti atoms in each cuboctahedron. In solid solution of $\mathrm{Si}$ in $\alpha$-Ti, $\mathrm{Si}$ atoms substitute $\mathrm{Ti}$ atoms, and, therefore, the local environment of each atom is also a cuboctahedron with slightly changed bond lengths. Indeed, the topology analysis confirms that in all eight structures each atom form cuboctahedron with one $\mathrm{Ti}$ or $\mathrm{Si}$ atom in its center and 12 surrounding atoms. The differences between these structures are in bond lengths and in the fraction of Si atoms; see descriptions of structures in Supplementary materials. We do not further consider these eight structures because the solubility limit of $\mathrm{Si}$ in $\alpha$-Ti is much lower than the fraction of $\mathrm{Si}$ in them, and, therefore, such structures should be unstable.

For the remaining 24 structures we calculated phonon dispersion curves to check their dynamical stability, and found that 10 structures are dynamically stable, while 14 structures are dynamically unstable. The dynamically stable structures are provided in the green rows, while the dynamically unstable structures are provided in the red rows in Table 3 .

\subsection{Comparison of the predicted structures with known structures}

To estimate the scientific novelty and completeness of the convex hull diagram for the Ti-Si system obtained in this study using USPEX, we checked how many binary structures predicted with the evolutionary algorithm are already known and stored in the existing databases or mentioned in the literature, and how many low-energy structures were not predicted before. To do this, firstly, we calculated the fingerprint distances between our predicted structures and binary Ti-Si structures from the Materials project [59], Open Quantum Materials [60,61], and AFLOWlib [62,90] databases. These databases were chosen because they are open, actively developing, contain information both about experimental and theoretically predicted structures, and have a convenient API interface for high-throughput extraction of data. Secondly, we calculated the fingerprint distances between our predicted structures and Ti-Si structures from the work of Colinet et al. [58] that are not included in these databases but have low formation energies and known to be stable in systems of early transition metals or rare earths with p-elements.

In the Materials project database there are only 12 binary $\mathrm{Ti}-\mathrm{Si}$ structures including stable ones, while in the Open Quantum Materials, and AFLOWlib databases the Ti-Si system is represented with 63 and 187 binary structures, respectively. We found that many TiSi structures in Open Quantum Materials, and AFLOWlib databases 
Table 3

Compositions (Comp.), symmetries (Spg. and No.), Pearson symbols, prototypes (if exist), formation energies ( $\left.E_{f}\right)$, and distances to the ground-state line (Stability) of the selected 32 low-energy metastable and unstable structures. The 8 of 32 structures that are assigned to the solid solutions of $\mathrm{Si}$ in $\alpha$-Ti are in the orange rows. The 10 of 32 structures that are dynamically stable are in the green rows, while the remaining 14 of 32 structures that are dynamically unstable are in the red rows. For the $\mathrm{Al}_{2} \mathrm{Cu}$-prototype $\mathrm{Ti}_{2} \mathrm{Si}$ (I4/mcm 140) structure, the comparison of its formation energy with those from literature [58] is shown.

\begin{tabular}{|c|c|c|c|c|c|c|}
\hline Comp. & Spg. & No. & $\begin{array}{l}\text { Pearson } \\
\text { symbol }\end{array}$ & Prot. & $\begin{array}{l}E_{f}, \\
\text { eV/atom }\end{array}$ & $\begin{array}{l}\text { Stability, } \\
\text { eV/atom }\end{array}$ \\
\hline $\mathrm{Ti}_{29} \mathrm{Si}$ & P1 & 1 & aP30 & & -0.051 & 0.018 \\
\hline $\mathrm{Ti}_{19} \mathrm{Si}$ & $\mathrm{Pm}$ & 6 & $\mathrm{mP} 20$ & & -0.082 & 0.020 \\
\hline $\mathrm{Ti}_{19} \mathrm{Si}$ & $\mathrm{Pm}$ & 6 & $\mathrm{mP20}$ & & -0.059 & 0.044 \\
\hline $\mathrm{Ti}_{15} \mathrm{Si}$ & Fmm2 & 42 & oS32 & & -0.093 & 0.035 \\
\hline $\mathrm{Ti}_{15} \mathrm{Si}$ & P1 & 1 & aP16 & & -0.087 & 0.041 \\
\hline $\mathrm{Ti}_{15} \mathrm{Si}$ & P1 & 1 & aP16 & & -0.097 & 0.032 \\
\hline $\mathrm{Ti}_{14} \mathrm{Si}$ & P1 & 1 & aP30 & & -0.101 & 0.035 \\
\hline $\mathrm{Ti}_{13} \mathrm{Si}$ & $\mathrm{C} 2$ & 5 & $\mathrm{mS} 28$ & & -0.116 & 0.030 \\
\hline $\mathrm{Ti}_{13} \mathrm{Si}$ & Amm2 & 38 & oP14 & & -0.114 & 0.033 \\
\hline $\mathrm{Ti}_{11} \mathrm{Si}$ & $\mathrm{C} 2$ & 5 & $\mathrm{mP12}$ & & -0.141 & 0.030 \\
\hline $\mathrm{Ti}_{11} \mathrm{Si}$ & P1 & 1 & aP12 & & -0.131 & 0.040 \\
\hline $\mathrm{Ti}_{9} \mathrm{Si}$ & $\mathrm{P} 2{ }_{1} / \mathrm{m}$ & 11 & $\mathrm{mP} 20$ & & -0.163 & 0.043 \\
\hline $\mathrm{Ti}_{9} \mathrm{Si}$ & $\mathrm{C} 2$ & 5 & $\mathrm{mP10}$ & & -0.164 & 0.041 \\
\hline $\mathrm{Ti}_{7} \mathrm{Si}$ & $\mathrm{P} 2{ }_{1} / \mathrm{m}$ & 11 & mP16 & & -0.224 & 0.033 \\
\hline $\mathrm{Ti}_{7} \mathrm{Si}$ & $\mathrm{P} \overline{1}$ & 2 & aP16 & & -0.224 & 0.033 \\
\hline $\mathrm{Ti}_{7} \mathrm{Si}$ & Pmmn & 59 & oP16 & & -0.217 & 0.040 \\
\hline $\mathrm{Ti}_{5} \mathrm{Si}$ & R32 & 155 & hR6 & & -0.292 & 0.050 \\
\hline $\mathrm{Ti}_{5} \mathrm{Si}$ & $\mathrm{P} \overline{1}$ & 2 & aP12 & & -0.292 & 0.050 \\
\hline $\mathrm{Ti}_{13} \mathrm{Si}_{3}$ & $\mathrm{P} 4 / \mathrm{mmm}$ & 123 & tP16 & & -0.303 & 0.082 \\
\hline $\mathrm{Ti}_{4} \mathrm{Si}$ & $\mathrm{P} \overline{1}$ & 2 & aP10 & & -0.381 & 0.030 \\
\hline $\mathrm{Ti}_{7} \mathrm{Si}_{2}$ & Fmmm & 69 & oF36 & & -0.395 & 0.061 \\
\hline $\mathrm{Ti}_{3} \mathrm{Si}$ & $\mathrm{Cmcm}$ & 63 & oS16 & & -0.472 & 0.041 \\
\hline $\mathrm{Ti}_{3} \mathrm{Si}$ & $\mathrm{Cmcm}$ & 63 & oS16 & $\mathrm{Cd}_{3} \mathrm{Y}$ & -0.466 & 0.047 \\
\hline $\mathrm{Ti}_{3} \mathrm{Si}$ & $\mathrm{C} 2$ & 5 & $\mathrm{mS} 24$ & & -0.466 & 0.047 \\
\hline $\mathrm{Ti}_{5} \mathrm{Si}_{2}$ & $\mathrm{R} \overline{3} \mathrm{~m}$ & 166 & hR7 & & -0.481 & 0.106 \\
\hline \multirow[t]{2}{*}{$\mathrm{Ti}_{2} \mathrm{Si}$} & \multirow[t]{2}{*}{$\mathrm{I} 4 / \mathrm{mcm}$} & \multirow[t]{2}{*}{140} & \multirow[t]{2}{*}{ tI12 } & \multirow[t]{2}{*}{$\mathrm{Al}_{2} \mathrm{Cu}$} & -0.679 & 0.005 \\
\hline & & & & & $-0.660[58]$ & 0.010 \\
\hline $\mathrm{Ti}_{9} \mathrm{Si}_{7}$ & P312 & 149 & hP16 & & -0.659 & 0.131 \\
\hline TiSi & $\mathrm{P} \overline{4} \mathrm{~m} 2$ & 115 & tP6 & & -0.656 & 0.114 \\
\hline $\mathrm{Ti}_{2} \mathrm{Si}_{3}$ & Immm & 71 & oI10 & & -0.529 & 0.116 \\
\hline $\mathrm{TiSi}_{2}$ & $\mathrm{R} \overline{3} \mathrm{~m}$ & 166 & hR3 & & -0.412 & 0.150 \\
\hline $\mathrm{Ti}_{7} \mathrm{Si}_{16}$ & $\mathrm{P} 4 / \mathrm{mmm}$ & 123 & tP23 & & -0.321 & 0.192 \\
\hline $\mathrm{TiSi}_{6}$ & $\mathrm{P} 6 / \mathrm{mmm}$ & 191 & hP7 & & -0.016 & 0.225 \\
\hline
\end{tabular}

are repeated, that is seen from their close formation energies, same stoichiometries, and same space groups. The part of the metastable or unstable Ti-Si structures from the Materials project, Open Quantum Materials, and AFLOWlib databases are known to be stable in other systems. Among them, there are $\mathrm{Cr}_{3} \mathrm{Si}$-prototype $\mathrm{Ti}_{3} \mathrm{Si}$ ( $\mathrm{Pm} \overline{3} \mathrm{n}$ 223) structure from OQMD that is stable in $\mathrm{V}-\mathrm{Si}, \mathrm{Cr}-\mathrm{Si}$, and Mo-Si systems, $\mathrm{Ni}_{3} \mathrm{Sn}$-prototype $\mathrm{Ti}_{3} \mathrm{Si}\left(\mathrm{P}_{3} / \mathrm{mmc}\right.$ 194) structure from OQMD and its counterpart from Materialsproject database that is stable in Ni-Sn, Ti$\mathrm{Sn}, \mathrm{Ti}-\mathrm{Ga}, \mathrm{Ti}-\mathrm{Al}, \mathrm{Re}-\mathrm{Pd}, \mathrm{Re}-\mathrm{Pt}$, and $\mathrm{Ti}-\mathrm{Pb}$ systems, $\mathrm{Al}_{2} \mathrm{Cu}$-prototype $\mathrm{Ti}_{2} \mathrm{Si}$ (I4/mcm 140) structure from AFLOWlib database, that is stable in $\mathrm{Zr}-\mathrm{Si}$, Hf-Si, Ta-Ni, Th-Ga, Pb-Au, Al-Hf, Al-Th, Zr-In, Zr-Ga, and Ta-Si systems, $\mathrm{Ti}_{5} \mathrm{Ga}_{4}$-prototype $\mathrm{Ti}_{5} \mathrm{Si}_{4}\left(\mathrm{PG}_{3} / \mathrm{mcm}^{193}\right)$ structure from AFLOWlib database that is stable Ti-Ga, Zr-Al, Zr-Sn, Hf-Sn, and ThSn systems, $\mathrm{Fe}_{2} \mathrm{P}$-prototype $\mathrm{Ti}_{2} \mathrm{Si}(\mathrm{P} \overline{6} 2 \mathrm{~m}$ 189) structure from OQMD that is stable in Ni-P system, and $\mathrm{CrB}$-prototype TiSi $(\mathrm{Cmcm} 63)$ structure from AFLOWlib database that is stable in Al-Zr, Al-Hf, Re-Ga, Re$\mathrm{Si}$, and Sn-La systems. The AFLOWlib and Open Quantum Materials databases also contain several low-energy structures that were not mentioned in the work of Colinet et al. [58]. Among them, there are $\mathrm{Ti}_{3} \mathrm{Si}$ ( $\mathrm{Cmcm}$ 63) structure from AFLOWlib database, $\mathrm{Ti}_{3} \mathrm{Si}\left(\mathrm{P}_{1} / \mathrm{m} \mathrm{11}\right)$, and $\mathrm{Ti}_{3} \mathrm{Si}$ (Pmmn 59) structures from Open Quantum Materials database. Other low-energy Ti-Si structures from [58] that are not included in the Materialsproject, Open Quantum Materials, and AFLOWlib databases represented by $\mathrm{Ni}_{3} \mathrm{P}$-prototype $\mathrm{Ti}_{3} \mathrm{Si}(\mathrm{I} \overline{4} 82)$ structure that is stable in $\mathrm{Zr}-\mathrm{Bi}, \mathrm{Hf}-\mathrm{Sb}$, and Ta-Ge systems, $\mathrm{Ni}_{2} \mathrm{In}$-prototype $\mathrm{Ti}_{2} \mathrm{Si}\left(\mathrm{P}_{3} / \mathrm{mmc}^{194}\right)$ structure that appears in Ce-In system, $\mathrm{W}_{5} \mathrm{Si}_{3}$-prototype $\mathrm{Ti}_{5} \mathrm{Si}_{3}(\mathrm{I} 4 / \mathrm{mcm}$ 140) structure that is stable in $\mathrm{W}-\mathrm{Si}, \mathrm{V}-\mathrm{Si}$, Mo-Si, and $\mathrm{Nb}-\mathrm{Ge}$ systems, $\mathrm{Nb}_{5} \mathrm{Si}_{3}$-prototype $\mathrm{Ti}_{5} \mathrm{Si}_{3}$ (I4/mcm 140) structure that is stable in $\mathrm{Nb}-\mathrm{Ge}$ system, $\mathrm{U}_{3} \mathrm{Si}_{2}$-prototype $\mathrm{Ti}_{3} \mathrm{Si}_{2}(\mathrm{P} 4 / \mathrm{mbm} \mathrm{127})$ structure that is stable in U-Si, Zr-Si, Th-Si, PU-Si, La-Si, Ce-Si, Hf-Ge, Th-Ge, Nb-Ga, Ta-Ga, $\mathrm{Th}-\mathrm{Ga}$, and $\mathrm{Zr}-\mathrm{Ga}$ systems, $\mathrm{Sm}_{5} \mathrm{Ge}_{4}$-prototype $\mathrm{Ti}_{5} \mathrm{Si}_{4}$ (Pnma 62) that is stable in $\mathrm{Nd}-\mathrm{Ge}, \mathrm{Tb}-\mathrm{Ge}, \mathrm{La}-\mathrm{Sn}, \mathrm{Y}-\mathrm{Ge}$, and other systems of rare-earth elements with $\mathrm{Si}, \mathrm{Ge}, \mathrm{Sn}$, or $\mathrm{Pb}$, and $\mathrm{CrSi}_{2}$-prototype $\mathrm{TiSi}_{2}\left(\mathrm{P}_{2} 22\right.$ 180) structure that appears in $\mathrm{V}-\mathrm{Si}, \mathrm{Nb}-\mathrm{Si}, \mathrm{Ta}-\mathrm{Si}$, and $\mathrm{Cr}-\mathrm{Si}$ systems [58].

We found that 70 of 1601 predicted binary structures excluding structures used as seeds have the same stoichiometric ratios and are topologically close to the one or several structures stored in the databases, as the Euclidean distances between their fingerprint vectors are less than 0.7. These structures are drawn as blue circles on the convex hull diagram; see Fig. 1. Among these 70 structures, there are three low-energy dynamically stable structures from Table $3, \mathrm{Al}_{2} \mathrm{Cu}$ prototype $\mathrm{Ti}_{2} \mathrm{Si}\left(\mathrm{I} 4 / \mathrm{mcm}_{140}\right), \mathrm{Ti}_{3} \mathrm{Si}$ (Cmcm 63), and $\mathrm{Cd}_{3} \mathrm{Y}$-prototype $\mathrm{Ti}_{3} \mathrm{Si}$ (Cmcm 63). The predicted $\mathrm{Al}_{2}$ Cu-prototype $\mathrm{Ti}_{2} \mathrm{Si}$ (I4/mcm 140) structure is totally coincide with $\mathrm{Ti}_{2} \mathrm{Si}(\mathrm{I} 4 / \mathrm{mcm} 140)$ structure from AFLOWlib database, as the Euclidean distance between fingerprint vectors of these structures is equal to 0.03 , while their distances 
to the ground-state line on our (Fig. 1) and AFLOW convex hull diagrams are differ by $1 \mathrm{meV} /$ atom. The predicted $\mathrm{Ti}_{3} \mathrm{Si}(\mathrm{Cmcm} \mathrm{63)}$ structure is topologically close to the low-energy $\mathrm{Ti}_{3} \mathrm{Si}(\mathrm{Cmcm} \mathrm{63)}$ structure from AFLOWlib database and to the low-energy $\mathrm{Ti}_{3} \mathrm{Si}(\mathrm{Pmmn}$ 59) structure from Open Quantum Materials database. The Euclidean distances between fingerprint vectors of these structures are 0.57 and 0.13 , while their stabilities on our (Fig. 1), AFLOW, and OQMD convex hull diagrams are differ by 6 and $27 \mathrm{meV} /$ atom, respectively. The $\mathrm{Cd}_{3} \mathrm{Y}$ prototype $\mathrm{Ti}_{3} \mathrm{Si}\left(\mathrm{Cmcm}\right.$ 63) structure is topologically close to the $\mathrm{Ti}_{3} \mathrm{Si}$ $\left(\mathrm{P} 2_{1} / \mathrm{m}\right.$ 11) structure from Open Quantum Materials database. The Euclidean distance between fingerprint vectors of these structures is 0.27, while their stabilities on our (Fig. 1) and OQMD convex hull diagrams are differ by $28 \mathrm{meV} /$ atom, respectively.

In the AFLOWlib database there are other four $\mathrm{Ti}_{3} \mathrm{Si}$ structures, namely $\mathrm{Ti}_{3} \mathrm{Si}$ (C2/m 12), $\mathrm{Ti}_{3} \mathrm{Si}$ (Pmm2 25), $\mathrm{Ti}_{3} \mathrm{Si}$ (Imm2 44), and $\mathrm{Ti}_{3} \mathrm{Si}$ (Pmmm 47), that are topologically close to the predicted $\mathrm{Ti}_{3} \mathrm{Si}(\mathrm{Cmcm}$ 63) structure but have lower symmetries while their distances to the ground-state line on the AFLOW convex hull diagram are much higher than that of the predicted $\mathrm{Ti}_{3} \mathrm{Si}(\mathrm{Cmcm}$ 63) structure on our convex hull diagram (Fig. 1). Because symmetries of these four structures are lower, they are, probably, represent undo relaxed structures of $\mathrm{Ti}_{3} \mathrm{Si}$ (Cmcm 63), that were stuck in different local minima of the potential energy. The fact that these structures have not slipped into one energy minimum during the relaxations indicates that the potential energy surface of the Ti-Si system is full of local minima at least at $\mathrm{Ti}_{3} \mathrm{Si}$ stoichiometry.

A comparison of the predicted by USPEX [63-66] structures with those from Colinet et al. [58], namely $\mathrm{Ni}_{3} \mathrm{Sn}$-prototype $\mathrm{Ti}_{3} \mathrm{Si}\left(\mathrm{P}_{3} / \mathrm{mmc}\right.$ 194), $\mathrm{Cr}_{3}$ Si-prototype $\mathrm{Ti}_{3} \mathrm{Si}$ ( $\mathrm{Pm} \overline{3} \mathrm{n}$ 223), $\mathrm{Ti}_{5} \mathrm{Ga}_{4}$-prototype $\mathrm{Ti}_{5} \mathrm{Si}_{4}$ ( $\mathrm{P}_{3} / \mathrm{mcm}$ 193), $\mathrm{Ni}_{3} \mathrm{P}$-prototype $\mathrm{Ti}_{3} \mathrm{Si}$ (I $\overline{4}$ 82), $\mathrm{Ni}_{2}$ In-prototype $\mathrm{Ti}_{2} \mathrm{Si}$ ( $\left.\mathrm{P}_{3} / \mathrm{mmc} 194\right), \mathrm{W}_{5} \mathrm{Si}_{3}$-prototype $\mathrm{Ti}_{5} \mathrm{Si}_{3}$ (I4/mcm 140), $\mathrm{Nb}_{5} \mathrm{Si}_{3}$ prototype $\mathrm{Ti}_{5} \mathrm{Si}_{3}$ (I4/mcm 140), $\mathrm{U}_{3} \mathrm{Si}_{2}$-prototype $\mathrm{Ti}_{3} \mathrm{Si}_{2}$ (P4/mbm 127), $\mathrm{Sm}_{5} \mathrm{Ge}_{4}$-prototype $\mathrm{Ti}_{5} \mathrm{Si}_{4}$ (Pnma 62), CrB-prototype TiSi (Cmcm 63), and $\mathrm{CrSi}_{2}$-prototype $\mathrm{TiSi}_{2}\left(\mathrm{P}_{2} 22\right.$ 180), showed us that one of our predicted metastable structures is coinciding with $\mathrm{Ni}_{2} \mathrm{In}$-prototype $\mathrm{Ti}_{2} \mathrm{Si}$ $\mathrm{Pb}_{3} / \mathrm{mmc}^{194)}$ structure, as the Euclidean distance between their fingerprint vectors is equal to 0.02 . This structure was not initially included in the list of structures that were selected for more detailed analysis (see Table 3 ) because it has formation energy higher than 50 meV above the ground-state line on the convex hull diagram in Fig. 1 and is not the most energetically favorable metastable structure at the $\mathrm{Ti}_{2} \mathrm{Si}$ composition. Other low-energy structures from Colinet et al. [58] do not coincide with predicted by USPEX [63-66] structures.

For further comparison of known from literature [58] and databases [59-62,90] low-energy structures with those from Table 3, we additionally relaxed these structures, calculated their formation energies with respect to the hexagonal close-packed (hcp) $\alpha$-Ti and cubic diamond $\mathrm{Si}$ at $0 \mathrm{~K}$ and $0 \mathrm{GPa}$, as well as phonon dispersion curves to check their dynamical stability. The information about compositions, space groups, Pearson symbols, prototypes, formation energies, and stabilities of these structures is presented in Table 4. It was found that seven structures are dynamically stable while four structures are dynamically unstable. Dynamically stable structures are in the green rows, while dynamically unstable structures are in the red rows of Table 4.

It is interesting that among the dynamically unstable structures there are $\mathrm{Sm}_{5} \mathrm{Ge}_{4}$-prototype $\mathrm{Ti}_{5} \mathrm{Si}_{4}$ (Pnma 62) and $\mathrm{Ni}_{3}$ P-prototype $\mathrm{Ti}_{3} \mathrm{Si}$ (I $\overline{4}$ 82) structures that are very close to the ground-state line on the convex-hull diagram.

Further in this work, we will discuss calculated thermodynamic stabilities, elastic and electronic properties of ten dynamically stable predicted structures from Table 3, and compare them with those of seven dynamically stable low-energy structures from the work Colinet et al. [58] and databases [59-62,90].
3.3. Thermodynamic stability of the low-energy structures in the Ti-Si system

According to the convex hull diagram in Fig. 1, the eight dynamically stable structures, $\mathrm{Ti}_{13} \mathrm{Si}_{3}$ (P4/mmm 123), $\mathrm{Ti}_{4} \mathrm{Si}$ (P1 2), $\mathrm{Ti}_{7} \mathrm{Si}_{2}$ (Fmmm 69), $\mathrm{Ti}_{3} \mathrm{Si}$ (Cmcm 63), $\mathrm{Cd}_{3} \mathrm{Y}$-prototype $\mathrm{Ti}_{3} \mathrm{Si}$ (Cmcm 63), $\mathrm{Ti}_{5} \mathrm{Si}_{2}$ ( $\mathrm{R} \overline{3} \mathrm{~m} \mathrm{166}), \mathrm{Ni}_{2} \mathrm{In}$-prototype $\mathrm{Ti}_{2} \mathrm{Si}\left(\mathrm{P}_{3} / \mathrm{mmc}^{194}\right)$, and $\mathrm{Al}_{2} \mathrm{Cu}$-prototype $\mathrm{Ti}_{2} \mathrm{Si}$ (I4/mcm 140), should decompose on $\mathrm{Ti}_{5} \mathrm{Si}_{3}\left(\mathrm{P}_{3} / \mathrm{mcm} \mathrm{193)}\right.$ and $\alpha$-Ti $\left(\mathrm{P}_{3} / \mathrm{mmc} 194\right)$, at $0 \mathrm{~K}$ and $0 \mathrm{GPa}$. The $\mathrm{U}_{3} \mathrm{Si}_{2}$-prototype $\mathrm{Ti}_{3} \mathrm{Si}_{2}$ (P4/mbm 127) structure should decompose on $\mathrm{Ti}_{5} \mathrm{Si}_{3}\left(\mathrm{P}_{3} / \mathrm{mcm}\right.$ 193) and $\mathrm{Ti}_{5} \mathrm{Si}_{4}\left(\mathrm{P} 4_{1} 2_{1} 2\right.$ 92), at $0 \mathrm{~K}$ and $0 \mathrm{GPa}$. The $\mathrm{TiSi}_{6}(\mathrm{P} 6 / \mathrm{mmm} \mathrm{191)}$ structure should decompose on $\mathrm{TiSi}_{2}(\mathrm{Cmcm} \mathrm{63)}$ and diamond $\mathrm{Si}(\mathrm{Fd} \overline{3} \mathrm{~m}$ 227) at $0 \mathrm{~K}$ and $0 \mathrm{GPa}$, while the $\mathrm{W}_{5} \mathrm{Si}_{3}$-prototype $\mathrm{Ti}_{5} \mathrm{Si}_{3}(\mathrm{I} 4 / \mathrm{mcm}$ 140), $\mathrm{Nb}_{5} \mathrm{Si}_{3}$-prototype $\mathrm{Ti}_{5} \mathrm{Si}_{3}$ (I4/mcm 140), $\mathrm{Ti}_{5} \mathrm{Ga}_{4}$-prototype $\mathrm{Ti}_{5} \mathrm{Si}_{4}$ ( $\left.\mathrm{P}_{3} / \mathrm{mcm} 193\right)$, TiSi (P̄̄m2 115), CrB-prototype TiSi (Cmcm 63), $\mathrm{CrSi}_{2}-$ prototype $\mathrm{TiSi}_{2}\left(\mathrm{P}_{2} 22\right.$ 180), and $\mathrm{TiSi}_{2}$ ( $\mathrm{R} \overline{\mathrm{m}}$ 166) structures should

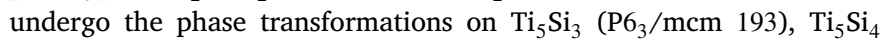
(P4 ${ }_{1} 2_{1} 2$ 92), TiSi (Pnma 62) or $\mathrm{TiSi}_{2}$ (Cmcm 63) that are stablest states at $0 \mathrm{~K}$ and $0 \mathrm{GPa}$ at given compositions, respectively.

The decomposition reactions are following:

$$
\begin{aligned}
& \mathrm{Ti}_{13} \mathrm{Si}_{3} \rightarrow \mathrm{Ti}_{5} \mathrm{Si}_{3} \text { (st.) }+8 \mathrm{Ti}+\Delta_{r} G^{\mathrm{Ti}_{13} \mathrm{Si}_{3},} \\
& 3 \mathrm{Ti}_{4} \mathrm{Si} \rightarrow \mathrm{Ti}_{5} \mathrm{Si}_{3} \text { (st.) }+7 \mathrm{Ti}+\Delta_{r} G^{\mathrm{Ti}_{4} \mathrm{Si}}, \\
& 3 \mathrm{Ti}_{7} \mathrm{Si}_{2} \rightarrow 2 \mathrm{Ti}_{5} \mathrm{Si}_{3} \text { (st.) }+11 \mathrm{Ti}+\Delta_{r} G^{\mathrm{Ti}_{7} \mathrm{Si}_{2}}, \\
& 3 \mathrm{Ti}_{3} \mathrm{Si} \rightarrow \mathrm{Ti}_{5} \mathrm{Si}_{3} \text { (st.) }+4 \mathrm{Ti}+\Delta_{r} G^{\mathrm{Ti}_{3} \mathrm{Si}}, \\
& 3 \mathrm{Ti}_{5} \mathrm{Si}_{2} \rightarrow 2 \mathrm{Ti}_{5} \mathrm{Si}_{3} \text { (st.) }+5 \mathrm{Ti}+\Delta_{r} G^{\mathrm{Ti}_{5} \mathrm{Si}_{2},} \\
& 3 \mathrm{Ti}_{2} \mathrm{Si} \rightarrow \mathrm{Ti}_{5} \mathrm{Si}_{3} \text { (st.) }+\mathrm{Ti}+\Delta_{r} G^{\mathrm{Ti}_{2} \mathrm{Si}}, \\
& 5 \mathrm{Ti}_{3} \mathrm{Si}_{2} \rightarrow 2 \mathrm{Ti}_{5} \mathrm{Si}_{3} \text { (st.) }+\mathrm{Ti}_{5} \mathrm{Si}_{4}+\Delta_{r} G^{\mathrm{Ti}_{3} \mathrm{Si}_{2}}, \\
& \mathrm{TiSi}_{6} \rightarrow \mathrm{TiSi}_{2} \text { (st.) }+4 \mathrm{Si}+\Delta_{r} G^{\mathrm{TiSi}_{6}}, \\
& \mathrm{Ti}_{5} \mathrm{Si}_{3} \text { (mst.) } \rightarrow \mathrm{Ti}_{5} \mathrm{Si}_{3} \text { (st.) }+\Delta_{r} G^{\mathrm{Ti}_{5} \mathrm{Si}_{3} \text { (mst.) }} \text {, } \\
& \mathrm{Ti}_{5} \mathrm{Si}_{4} \text { (mst.) } \rightarrow \mathrm{Ti}_{5} \mathrm{Si}_{4} \text { (st.) }+\Delta_{r} G^{\mathrm{Ti}_{5} \mathrm{Si}_{4} \text { (mst.) }} \\
& \mathrm{TiSi}(\mathrm{mst} .) \rightarrow \mathrm{TiSi}(\mathrm{st} .)+\Delta_{r} G^{\mathrm{TiSi}(\mathrm{mst} .)} \text {, } \\
& \mathrm{TiSi}_{2} \text { (mst.) } \rightarrow \mathrm{TiSi}_{2} \text { (st.) }+\Delta_{r} G^{\mathrm{TiSi}_{2} \text { (mst.) }} \text {, }
\end{aligned}
$$

where $\Delta_{r} G^{\mathrm{Ti}_{x} \mathrm{Si}_{y}}$ are the changes in the free energy in the reactions of decomposition of corresponding $\mathrm{Ti}_{x} \mathrm{Si}_{y}$ compounds, (st.) denote the stable structures at $0 \mathrm{~K}$ and $0 \mathrm{GPa}$ for a given composition, (mst.) denote the metastable structures.

The changes in the free energy in decomposition reactions reflect the thermodynamic stability of structures. The positive change means that structure should decompose on more stable structure(s), while negative change means that this structure is the stablest at given composition. At $0 \mathrm{~K}$ and $0 \mathrm{GPa}$, the changes in the free energy, $\Delta_{r} G^{\mathrm{Ti}_{x} \mathrm{Si}_{y}}$, in decomposition reactions (3)-(14) normalized per atom of (see Supplementary materials) correspond to the energies above the ground-state line on the convex hull diagram in Fig. 1 which are given in column "Stability" in Tables 1, 3 and 4. Knowing the temperature or pressure dependencies of $\Delta_{r} G^{\mathrm{Ti}_{x} \mathrm{Si}_{y}}$, we can estimate the thermodynamic stability and possibility of stabilization of metastable structures with temperature or pressure.

In this work, we calculated the temperature dependencies, $\Delta_{r} G^{\mathrm{Ti}_{x} \mathrm{Si}_{y}}$ $(T)$, for dynamically stable structures in the harmonic approximation neglecting the volume dependence and electronic contributions to the free energy. In this way, the dependence of the change in the Gibbs free energy, $\Delta_{r} G^{\mathrm{Ti}_{x} \mathrm{Si}_{y}}(T)$, becomes numerically equal to the dependence of the change in the Helmholtz free energy, $\Delta_{r} F^{\mathrm{Ti}_{x} \mathrm{Si}_{y}}(T)$ :

$\Delta_{r} G^{\mathrm{Ti}_{x} \mathrm{Si}_{y}}(T)=\Delta_{r} F^{\mathrm{Ti}_{\mathrm{x}} \mathrm{Si}_{\mathrm{y}}}(T)=\Delta_{r} E_{0}^{\mathrm{Ti}_{\mathrm{x}} \mathrm{Si}_{\mathrm{y}}}+\Delta_{r} F_{\text {vib }}^{\mathrm{Ti}_{\mathrm{x}} \mathrm{Si}_{\mathrm{y}}}(T)$,

where $\Delta_{r} E_{0}^{\mathrm{Ti}_{\mathrm{x}} \mathrm{Si}_{\mathrm{y}}}$ and $\Delta_{r} F_{\mathrm{vib}}^{\mathrm{Ti}_{\mathrm{x}} \mathrm{Si}_{\mathrm{y}}}(T)$ are the ground-state and vibrational contributions to the change of the free energy in the decomposition reaction, respectively. 
Table 4

Compositions (Comp.), symmetries (Spg. and No.), formation energies ( $\left.E_{f}\right)$, and distances to the ground-state line (Stability) of the three low-energy metastable and unstable structures from Materialsproject [59], Open Quantum Materials [60,61], and AFLOWlib [62,90] databases in comparison with available DFT data [58$62,90]$. The dynamically stable structures are in the green rows, while the dynamically unstable structures are in the red rows.

\begin{tabular}{|c|c|c|c|c|c|c|}
\hline Comp. & Spg. & No. & $\begin{array}{l}\text { Pearson } \\
\text { symbol }\end{array}$ & Prot. & $\begin{array}{l}E_{f}, \\
\text { eV/atom }\end{array}$ & $\begin{array}{l}\text { Stability, } \\
\text { eV/atom }\end{array}$ \\
\hline $\mathrm{Ti}_{3} \mathrm{Si}$ & $\mathrm{P}_{3} / \mathrm{mmc}$ & 194 & hP8 & $\mathrm{Ni}_{3} \mathrm{Sn}$ & $\begin{array}{l}-0.463 \\
-0.455[58] \\
-0.516[60,61] \\
-0.462[59]\end{array}$ & $\begin{array}{l}0.050 \\
0.046 \\
0.019 \\
0.052\end{array}$ \\
\hline $\mathrm{Ti}_{3} \mathrm{Si}$ & $\operatorname{Pm} \overline{3} n$ & 223 & cP8 & $\mathrm{Cr}_{3} \mathrm{Si}$ & $\begin{array}{l}-0.441 \\
-0.439[58] \\
-0.509[60,61]\end{array}$ & $\begin{array}{l}0.072 \\
0.062 \\
0.026\end{array}$ \\
\hline $\mathrm{Ti}_{3} \mathrm{Si}$ & $\mathrm{I} \overline{4}$ & 82 & tI32 & $\mathrm{Ni}_{3} \mathrm{P}$ & $\begin{array}{l}-0.493 \\
-0.472[58]\end{array}$ & $\begin{array}{l}0.021 \\
0.030\end{array}$ \\
\hline $\mathrm{Ti}_{2} \mathrm{Si}$ & $\mathrm{P}_{3} / \mathrm{mmc}$ & 194 & hP6 & $\mathrm{Ni}_{2}$ In & $\begin{array}{l}-0.624 \\
-0.616[58]\end{array}$ & $\begin{array}{l}0.061 \\
0.054\end{array}$ \\
\hline $\mathrm{Ti}_{5} \mathrm{Si}_{3}$ & $\mathrm{I} 4 / \mathrm{mcm}$ & 140 & tI32 & $\mathrm{Nb}_{5} \mathrm{Si}_{3}$ & $\begin{array}{l}-0.720 \\
-0.704[58]\end{array}$ & $\begin{array}{l}0.051 \\
0.048\end{array}$ \\
\hline $\mathrm{Ti}_{5} \mathrm{Si}_{3}$ & $\mathrm{I} 4 / \mathrm{mcm}$ & 140 & tI32 & $\mathrm{W}_{5} \mathrm{Si}_{3}$ & $\begin{array}{l}-0.745 \\
-0.730[58]\end{array}$ & $\begin{array}{l}0.025 \\
0.022\end{array}$ \\
\hline $\mathrm{Ti}_{3} \mathrm{Si}_{2}$ & $\mathrm{P} 4 / \mathrm{mbm}$ & 127 & tP10 & $\mathrm{U}_{3} \mathrm{Si}_{2}$ & $\begin{array}{l}-0.767 \\
-0.746[58]\end{array}$ & $\begin{array}{l}0.011 \\
0.010\end{array}$ \\
\hline $\mathrm{Ti}_{5} \mathrm{Si}_{4}$ & $\mathrm{P}_{3} / \mathrm{mcm}$ & 193 & hP18 & $\mathrm{Ti}_{5} \mathrm{Ga}_{4}$ & $\begin{array}{l}-0.743 \\
-0.716[58] \\
-0.744[62,90]\end{array}$ & $\begin{array}{l}0.048 \\
0.058 \\
0.049\end{array}$ \\
\hline $\mathrm{Ti}_{5} \mathrm{Si}_{4}$ & Pnma & 62 & oP36 & $\mathrm{Sm}_{5} \mathrm{Ge}_{4}$ & $\begin{array}{l}-0.788 \\
-0.770[58]\end{array}$ & $\begin{array}{l}0.003 \\
0.003\end{array}$ \\
\hline TiSi & $\mathrm{Cmcm}$ & 63 & oC8 & $\mathrm{CrB}$ & $\begin{array}{l}-0.765 \\
-0.747[58] \\
-0.769[62,90]\end{array}$ & $\begin{array}{l}0.004 \\
0.002 \\
0.001\end{array}$ \\
\hline $\mathrm{TiSi}_{2}$ & $\mathrm{P}_{2} 22$ & 180 & hP9 & $\mathrm{CrSi}_{2}$ & $\begin{array}{l}-0.537 \\
-0.501\end{array}$ & $\begin{array}{l}0.025 \\
0.030\end{array}$ \\
\hline
\end{tabular}

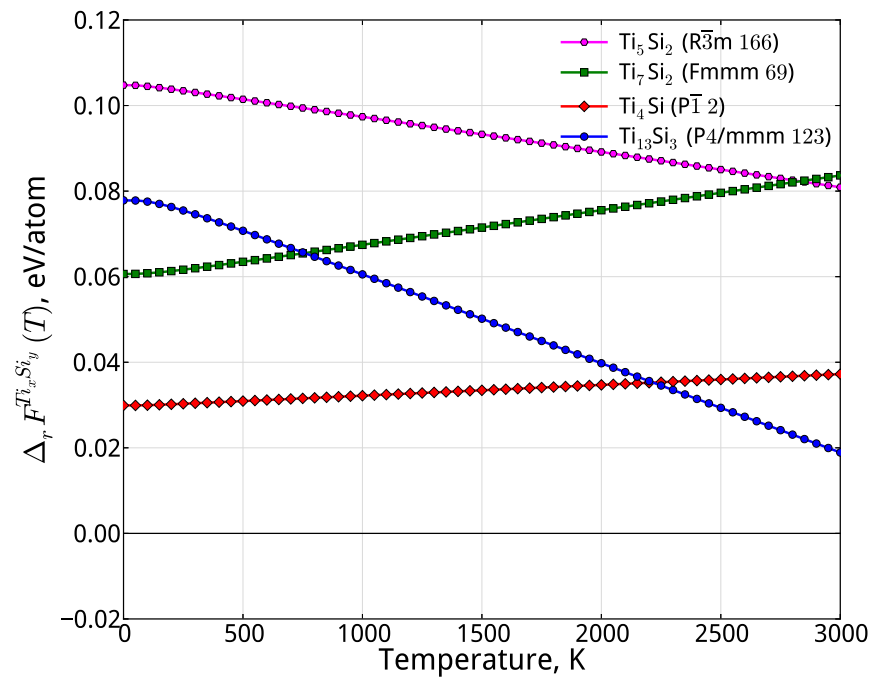

Fig. 2. The temperature dependencies of the free energy change, $\Delta_{r} F^{\mathrm{Ti}_{x} \mathrm{Si}_{y}}(T)$, in the decomposition reactions (3)-(5) and (7) for $\mathrm{Ti}_{13} \mathrm{Si}_{3}$ (P4/mmm 123), $\mathrm{Ti}_{4} \mathrm{Si}$ (P1 2), $\mathrm{Ti}_{7} \mathrm{Si}_{2}$ (Fmmm 69), and $\mathrm{Ti}_{5} \mathrm{Si}_{2}$ (R $\overline{3} \mathrm{~m}$ 166) structures.

The temperature dependencies of $\Delta_{r} F^{\mathrm{Ti}_{x} \mathrm{Si}_{y}}(T)$ in the reactions (3)(5) and (7) for $\mathrm{Ti}_{13} \mathrm{Si}_{3}$ (P4/mmm 123), $\mathrm{Ti}_{4} \mathrm{Si}\left(\mathrm{P}^{\overline{1}} 2\right), \mathrm{Ti}_{7} \mathrm{Si}_{2}$ (Fmmm 69), and $\mathrm{Ti}_{5} \mathrm{Si}_{2}(\mathrm{R} \overline{3} \mathrm{~m}$ 166) structures are shown in Fig. 2.

As it is seen from Fig. 2, two Ti-rich structures, $\mathrm{Ti}_{5} \mathrm{Si}_{2}$ ( $\mathrm{R} \overline{3} \mathrm{~m}$ 166) and $\mathrm{Ti}_{13} \mathrm{Si}_{3}$ (P4/mmm 123), tend to be thermodynamically stabilized with temperature with respect to the $\mathrm{Ti}_{5} \mathrm{Si}_{3}\left(\mathrm{P}_{3} / \mathrm{mcm} \mathrm{193)}\right.$ and $\alpha$-Ti $\left(\mathrm{P}_{3} / \mathrm{mmc} 194\right)$. However, the large positive $\Delta_{r} F^{\mathrm{Ti}_{x} \mathrm{Si}_{y}}$ at $0 \mathrm{~K}$ prevent their stabilization up to melting temperature which vary from 1840 to $2400 \mathrm{~K}$ in composition range of possible existence of these structures according to the experimentally-based phase diagram of the Ti-Si system [13]. Other two Ti-rich structures, $\mathrm{Ti}_{4} \mathrm{Si}(\mathrm{P} \overline{1} 2)$ and $\mathrm{Ti}_{7} \mathrm{Si}_{2}$ (Fmmm 69), tend to be further thermodynamically destabilized with temperature.

The temperature dependencies of $\Delta_{r} F^{\mathrm{Ti}_{x} \mathrm{Si}_{y}}(T)$ in the reaction (6) for $\mathrm{Ti}_{3} \mathrm{Si}\left(\mathrm{Cmcm} \mathrm{63)}\right.$ and $\mathrm{Cd}_{3} \mathrm{Y}$-prototype $\mathrm{Ti}_{3} \mathrm{Si}(\mathrm{Cmcm} \mathrm{63)} \mathrm{structures}$ are shown in Fig. 3, where, for comparison, the same dependence of $\Delta_{r} F^{\mathrm{Ti}_{x} \mathrm{Si}_{y}}(T)$ for the experimental $\mathrm{Ti}_{3} \mathrm{P}$-prototype $\mathrm{Ti}_{3} \mathrm{Si}\left(\mathrm{P} 4_{2} / \mathrm{n} 86\right)$ structure calculated in our previous work [72] is also plotted.

It is seen, that more energetically favorable at $0 \mathrm{~K} \mathrm{Ti}{ }_{3} \mathrm{Si}(\mathrm{Cmcm} 63)$ structure becomes by $\sim 5 \mathrm{meV} /$ atom less favorable with temperature, while the energetically less favorable at $0 \mathrm{~K} \mathrm{Cd} \mathrm{Cd}_{3} \mathrm{Y}$-prototype $\mathrm{Ti}_{3} \mathrm{Si}$ (Cmcm 63) structure becomes by $\sim 10 \mathrm{meV} /$ atom more favorable with temperature due to the lattice vibrations. However, with strong concurrency of the $\mathrm{Ti}_{3} \mathrm{P}$-prototype $\mathrm{Ti}_{3} \mathrm{Si}\left(\mathrm{P}_{2} / \mathrm{n}\right.$ 86) structure, it is highly unlikely that $\mathrm{Cd}_{3} \mathrm{Y}$-prototype $\mathrm{Ti}_{3} \mathrm{Si}(\mathrm{Cmcm} 63)$ could be formed in the Ti-Si system.

The temperature dependencies of $\Delta_{r} F^{\mathrm{Ti}_{x} \mathrm{Si}_{y}}(T)$ in the reaction (8) for $\mathrm{Ni}_{2} \mathrm{In}$-prototype $\mathrm{Ti}_{2} \mathrm{Si}\left(\mathrm{P}_{3} / \mathrm{mmc} 194\right)$ and $\mathrm{Al}_{2} \mathrm{Cu}$-prototype $\mathrm{Ti}_{2} \mathrm{Si}$ (I4/mcm 140) are shown in Fig. 4, where, for comparison, the same dependence of $\Delta_{r} F^{\mathrm{Ti}_{x} \mathrm{Si}_{y}}(T)$ for $\mathrm{Fe}_{2} \mathrm{P}$-prototype $\mathrm{Ti}_{2} \mathrm{Si}(\mathrm{P} \overline{6} 2 \mathrm{~m} 189)$ structure calculated in our previous work [72] is also plotted.

From literature, it is known that $\mathrm{Fe}_{2} \mathrm{P}$-prototype $\mathrm{Ti}_{2} \mathrm{Si}(\mathrm{P} \overline{6} 2 \mathrm{~m} \mathrm{189})$ structure was never observed in the binary Ti-Si system but many times was observed in the Ti-Si-Zr system and higher-order systems containing it as a subsystem $[29,42,43,48]$. DFT calculations revealed that $\mathrm{Ti}_{2} \mathrm{Si}(\mathrm{P} \overline{6} 2 \mathrm{~m} \mathrm{189})$ is thermodynamically destabilizes with respect to $\mathrm{Ti}_{5} \mathrm{Si}_{3}\left(\mathrm{P}_{3} / \mathrm{mcm} 193\right)$ and $\alpha$-Ti $\left(\mathrm{P}_{3} / \mathrm{mmc} 194\right)$ due to the lattice vibrations [72] but stabilizes with partial substitution of Ti atoms with Zr atoms [92]. 


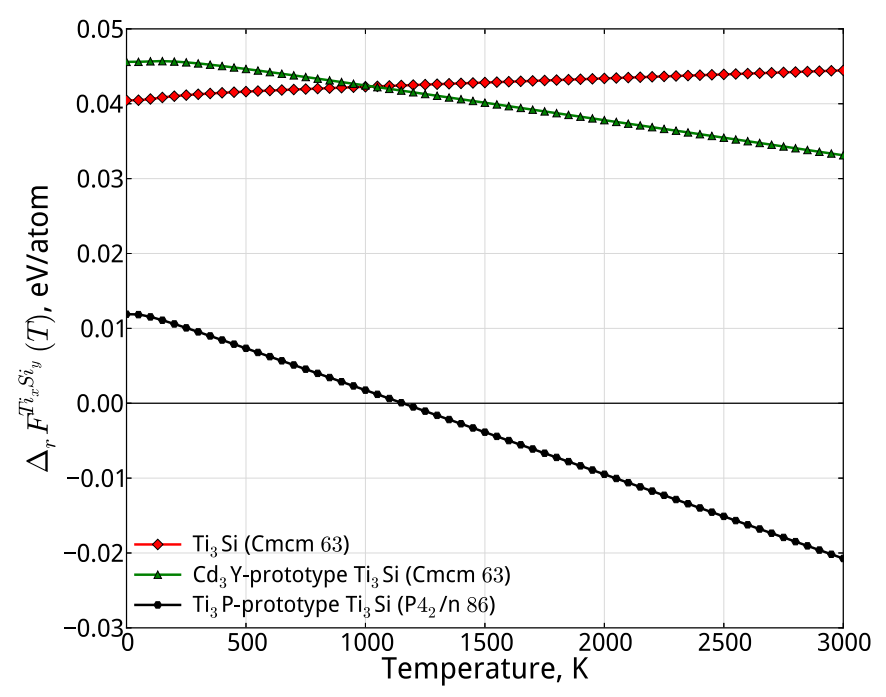

Fig. 3. The temperature dependencies of the free energy change, $\Delta_{r} F^{\mathrm{Ti}_{x} \mathrm{Si}_{y}}(T)$, in the decomposition reaction (6) for $\mathrm{Ti}_{3} \mathrm{Si}\left(\mathrm{Cmcm} \mathrm{63)}, \mathrm{Cd}_{3} \mathrm{Y}\right.$-prototype $\mathrm{Ti}_{3} \mathrm{Si}(\mathrm{Cmcm} \mathrm{63)}$ ), and $\mathrm{Ti}_{3} \mathrm{P}$-prototype $\mathrm{Ti}_{3} \mathrm{Si}\left(\mathrm{P}_{2} / \mathrm{n} 86\right)$ structures.

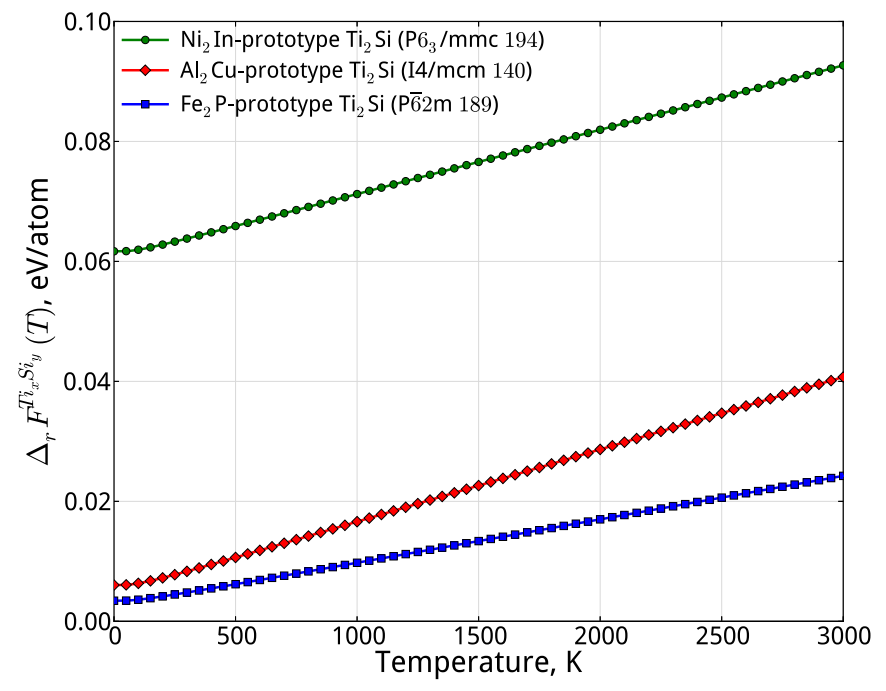

Fig. 4. The temperature dependencies of the free energy change, $\Delta_{r} F^{\mathrm{Ti}_{x} \mathrm{Si}_{y}}(T)$, in the decomposition reaction (8) for $\mathrm{Ni}_{2}$ In-prototype $\mathrm{Ti}_{2} \mathrm{Si}\left(\mathrm{P6}_{3} / \mathrm{mmc} 194\right), \mathrm{Al}_{2} \mathrm{Cu}$-prototype $\mathrm{Ti}_{2} \mathrm{Si}$ (I4/mcm 140), and $\mathrm{Fe}_{2} \mathrm{P}$-prototype $\mathrm{Ti}_{2} \mathrm{Si}(\mathrm{P} \overline{6} 2 \mathrm{~m} \mathrm{189})$ structures.

In contrast to $\mathrm{Ti}_{2} \mathrm{Si}\left(\mathrm{P} \overline{6} 2 \mathrm{~m}\right.$ 189), the information about the $\mathrm{Al}_{2} \mathrm{Cu}$ prototype $\mathrm{Ti}_{2} \mathrm{Si}(\mathrm{I} 4 / \mathrm{mcm} 140)$ and $\mathrm{Ni}_{2}$ In-prototype $\mathrm{Ti}_{2} \mathrm{Si}\left(\mathrm{P}_{3} / \mathrm{mmc}\right.$ 194) structures is scarce. From the literature data [58] and databases [62] only their formation energies at $0 \mathrm{~K}$ can be derived. From Fig. 4, it is seen that $\mathrm{Al}_{2} \mathrm{Cu}$-prototype $\mathrm{Ti}_{2} \mathrm{Si}(\mathrm{I} 4 / \mathrm{mcm} 140)$ and $\mathrm{Ni}_{2} \mathrm{In}$-prototype $\mathrm{Ti}_{2} \mathrm{Si}\left(\mathrm{P}_{3} / \mathrm{mmc} 194\right)$ are thermodynamically destabilized by vibrational contributions to the free energy as well as $\mathrm{Fe}_{2} \mathrm{P}$-prototype $\mathrm{Ti}_{2} \mathrm{Si}(\mathrm{P} \overline{6} 2 \mathrm{~m}$ 189). This is, most likely, the main reason why these structures were never observed in the binary Ti-Si system.

The temperature dependencies of $\Delta_{r} F^{\mathrm{Ti}_{x} \mathrm{Si}_{y}}(T)$ in the reactions (9), (11), and (12), for $\mathrm{U}_{3} \mathrm{Si}_{2}$-prototype $\mathrm{Ti}_{3} \mathrm{Si}_{2} \quad$ (P4/mbm 127), $\mathrm{W}_{5} \mathrm{Si}_{3}$-prototype $\mathrm{Ti}_{5} \mathrm{Si}_{3}$ (I4/mcm 140), $\mathrm{Nb}_{5} \mathrm{Si}_{3}$-prototype $\mathrm{Ti}_{5} \mathrm{Si}_{3}$ (I4/mcm 140), and $\mathrm{Ti}_{5} \mathrm{Ga}_{4}$-prototype $\mathrm{Ti}_{5} \mathrm{Si}_{4}\left(\mathrm{P}_{3} / \mathrm{mcm} \mathrm{193}\right)$ are shown in Fig. 5.

It is seen, that $\mathrm{W}_{5} \mathrm{Si}_{3}$-prototype $\mathrm{Ti}_{5} \mathrm{Si}_{3}(\mathrm{I} 4 / \mathrm{mcm} 140)$ and $\mathrm{Nb}_{5} \mathrm{Si}_{3}$ prototype $\mathrm{Ti}_{5} \mathrm{Si}_{3}$ (I4/mcm 140) structures become slightly more stable with temperature, gaining not more than $5 \mathrm{meV} /$ atom in their formation energies, while $\mathrm{Ti}_{5} \mathrm{Ga}_{4}$-prototype $\mathrm{Ti}_{5} \mathrm{Si}_{4}\left(\mathrm{P}_{3} / \mathrm{mcm}\right.$ 193) gains up to $30 \mathrm{meV} /$ atom in its formation energy at high temperatures due to

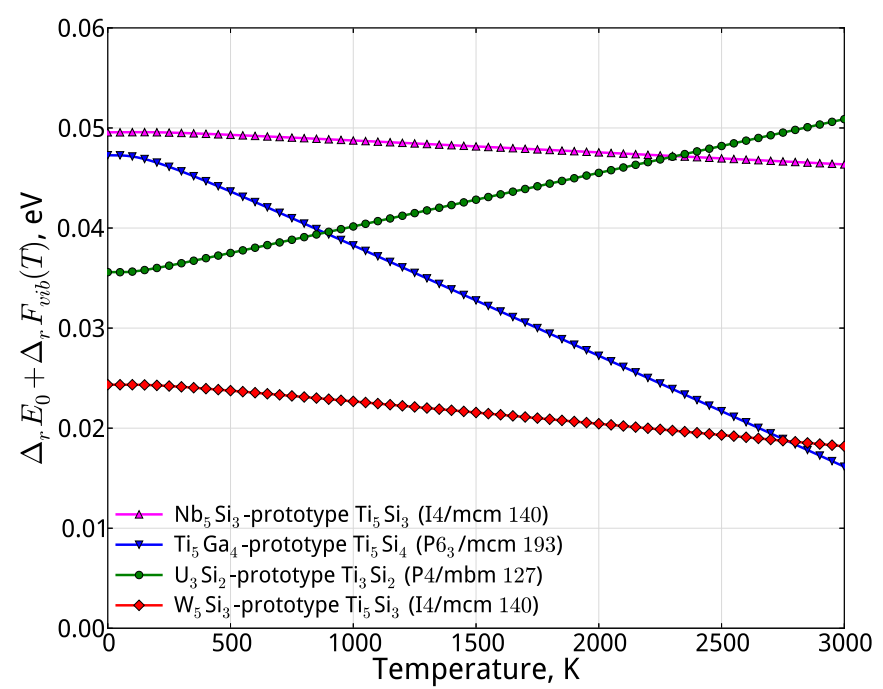

Fig. 5. The temperature dependencies of the free energy change, $\Delta_{r} F^{\mathrm{Ti}_{x} \mathrm{Si}_{y}}(T)$, in the decomposition reactions (9), (11), and (12), for $\mathrm{U}_{3} \mathrm{Si}_{2}$-prototype $\mathrm{Ti}_{3} \mathrm{Si}_{2}(\mathrm{P} 4 / \mathrm{mbm}$ 127), $\mathrm{W}_{5} \mathrm{Si}_{3}$-prototype $\mathrm{Ti}_{5} \mathrm{Si}_{3}$ (I4/mcm 140), $\mathrm{Nb}_{5} \mathrm{Si}_{3}$-prototype $\mathrm{Ti}_{5} \mathrm{Si}_{3}$ (I4/mcm 140), and $\mathrm{Ti}_{5} \mathrm{Ga}_{4}$-prototype $\mathrm{Ti}_{5} \mathrm{Si}_{4}\left(\mathrm{PG}_{3} / \mathrm{mcm} \mathrm{193}\right)$ structures.

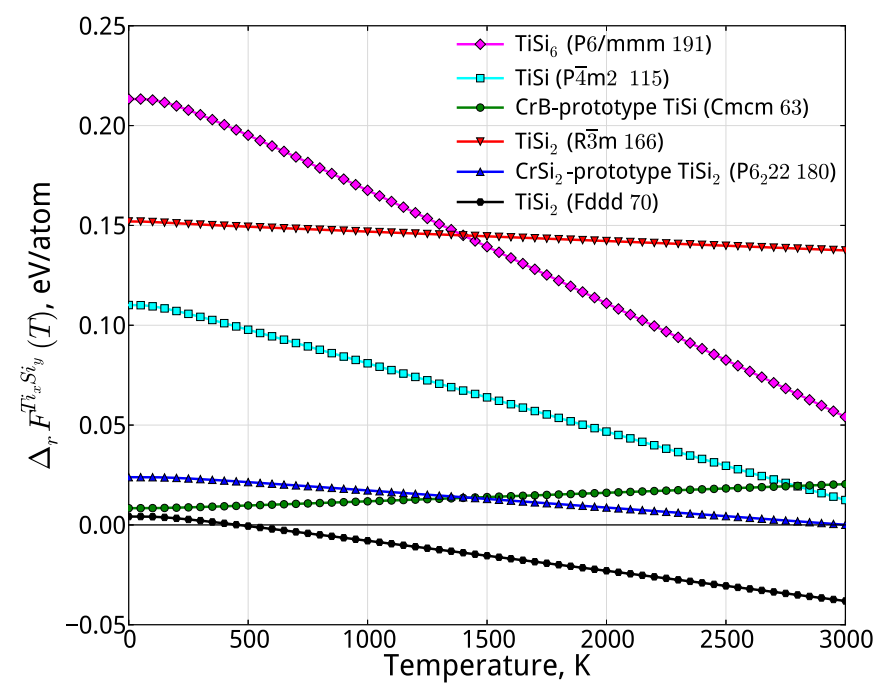

Fig. 6. The temperature dependencies of the free energy change, $\Delta_{r} F^{\mathrm{Ti}_{x} \mathrm{Si}_{y}}(T)$, in the decomposition reactions (10), (13), and (14) for $\mathrm{TiSi}_{6}$ (P6/mmm 191), TiSi ( $\mathrm{P} \overline{4} \mathrm{~m} 2$ 115), CrB-prototype TiSi (Cmcm 63), $\mathrm{CrSi}_{2}$-prototype $\mathrm{TiSi}_{2}\left(\mathrm{P}_{2} 22\right.$ 180), $\mathrm{TiSi}_{2}(\mathrm{R} \overline{3} \mathrm{~m})$, and $\mathrm{TiSi}_{2}$ (Fddd 70) structures.

the lattice vibrations. However, such energy gains are not sufficient for the thermodynamical stabilization of these structures even at $3000 \mathrm{~K}$. $\mathrm{U}_{3} \mathrm{Si}_{2}$-prototype $\mathrm{Ti}_{3} \mathrm{Si}_{2}$ (P4/mbm 127) structure, on the contrary, lose up to $15 \mathrm{meV} /$ atom in its thermodynamic stability due to the lattice vibrations.

The temperature dependencies of $\Delta_{r} F^{\mathrm{Ti}_{x} \mathrm{Si}_{y}}(T)$ in the reactions (10), (13), and (14) for $\mathrm{TiSi}_{6}$ (P6/mmm 191), TiSi (P4̄m2 115), CrB-prototype TiSi (Cmcm 63), $\mathrm{CrSi}_{2}$-prototype $\mathrm{TiSi}_{2}\left(\mathrm{P}_{2} 22\right.$ 180) and $\mathrm{TiSi}_{2}$ (R $\left.\overline{3} \mathrm{~m} \mathrm{166}\right)$ are shown on Fig. 6, where for, for comparison, the same dependence of $\Delta_{r} F^{\mathrm{Ti}_{x} \mathrm{Si}_{y}}(T)$ for the experimental $\mathrm{TiSi}_{2}$ (Fddd 70) structure calculated in our previous work [72] is also plotted.

The steepest negative slope of the $\Delta_{r} F^{\mathrm{Ti}_{x} \mathrm{Si}_{y}}(T)$ has the predicted Si-rich $\mathrm{TiSi}_{6}(\mathrm{P} 6 / \mathrm{mmm} \mathrm{191})$ structure. It gains up to $170 \mathrm{meV} /$ atom in its formation energy with temperature. Another predicted structure with equiatomic composition, TiSi ( $\mathrm{P} \overline{4} \mathrm{~m} 2$ 115), gains up to 100 $\mathrm{meV} /$ atom due to the lattice vibrations. However, because of large initial distance to the ground-state line on the convex hull diagram at 
$0 \mathrm{~K}$, these structures do not become the stablest states. The predicted $\mathrm{TiSi}_{2}(\mathrm{R} \overline{3} \mathrm{~m})$ structure becomes more stable up to $10 \mathrm{meV} /$ atom, while the CrB-prototype TiSi (Cmcm 63) structure becomes less stable by 10 $\mathrm{meV} /$ atom with temperature.

The $\mathrm{CrSi}_{2}$-prototype $\mathrm{TiSi}_{2}\left(\mathrm{P}_{2} 22\right.$ 180) is the only structure that have a chance to be stabilized with respect to $\mathrm{TiSi}_{2}(\mathrm{Cmcm} \mathrm{63)}$ and diamond $\mathrm{Si}(\mathrm{Fd} \overline{3} \mathrm{~m} 227)$ due to the vibrational free energy. However, there are two reasons why this structure does not become the stablest state at given composition. First, the temperature of stabilization of $\mathrm{CrSi}_{2}$-prototype $\mathrm{TiSi}_{2}\left(\mathrm{P}_{2} 22\right.$ 180) structure is higher than melting temperature of a Ti-Si alloy at given composition according to the experimentally-based phase diagram [13]. Second, it has a strong concurrency with the experimentally observed $\mathrm{TiSi}_{2}$ (Fddd 70) structure that is metastable at $0 \mathrm{~K}$ and becomes the stablest state at temperatures higher than $450 \mathrm{~K}$.

Concluding this subsection, we can say that none of the predicted metastable structures is thermodynamically stabilized with temperature due to the lattice vibrations. Meanwhile, the question of their stabilization with pressure or with the addition of other elements is still open.

3.4. Mechanical properties of the low-energy metastable structures in the Ti-Si system

The elastic constants, $C_{i j}$, of dynamically stable Ti-Si structures and their averaged polycrystalline quantities, bulk moduli $B$, Young's moduli $E$, shear moduli $G$, and Poisson's ratios $v$, are summarized in Table 5, where the structures are ordered by increasing of the $\mathrm{Si}$ fraction in them.

As it is seen from Table 5, all structures are mechanically stable. There are trends in decreasing of Poisson's ratio $v$ and $B / G$ ratio with fraction of $\mathrm{Si}$ in structures. The $B / G$ ratio is a measure of brittleductile behavior. Its value less than 1.75 indicates the brittle mechanical behavior of a structure, while the $B / G$ value more than 2 indicates that the structure should be ductile [93].

In Table 5 there are three obviously ductile structures having $B / G>$ 2 with $\mathrm{Ti}_{13} \mathrm{Si}_{3}$ and $\mathrm{Ti}_{3} \mathrm{Si}$ compositions, and four rather ductile than brittle structures having $1.75<B / G<2$ with $\mathrm{Ti}_{4} \mathrm{Si}_{1}, \mathrm{Ti}_{5} \mathrm{Si}_{2}, \mathrm{Ti}_{5} \mathrm{Si}_{3}$, and TiSi compositions. Other ten structures should exhibit a brittle behavior as their $B / G$ ratios are less than 1.75 .

\subsection{Electronic band structures and densities of states of the low-energy metastable structures in the Ti-Si system}

The electronic band structures and densities of states (elDOS) of the dynamically stable low-energy metastable structures in the Ti-Si system are provided in the Supplementary materials. All studied structures are metallic since there are no energy gaps between occupied and unoccupied states at the Fermi level. The main contributions to the elDOS on the Fermi level are from the $d$-states of Ti atoms for all structures.

Among the considered structures, two structures, $\mathrm{Ti}_{5} \mathrm{Si}_{2}$ ( $\mathrm{R} \overline{\mathrm{m}} \mathrm{m} 166$ ) and $\mathrm{Ni}_{2}$ In-prototype $\mathrm{Ti}_{2} \mathrm{Si}\left(\mathrm{P}_{3} / \mathrm{mmc} 194\right)$, can be emphasized. The $\mathrm{Ti}_{5} \mathrm{Si}_{2}$ ( $\mathrm{R} \overline{3} \mathrm{~m}$ 166) structure, that was predicted by the evolutionary algorithm in this work for the first time, has three direct energy gaps in its electronic band structure at energies $\sim 250 \mathrm{meV}$ higher than the Fermi level; see Fig. 7. If it would be possible to raise the Fermi level of this structure by $200-300 \mathrm{meV}$ and stabilize it with respect to $\mathrm{Ti}_{5} \mathrm{Si}_{3}$ ( $\left.\mathrm{P}_{3} / \mathrm{mcm} 193\right)$ and $\alpha$-Ti $\left(\mathrm{P}_{3} / \mathrm{mmc} 194\right)$ without changing the direct bandgaps, e.g. by doping with additional elements, this structure would be useful in photovoltaic or thermoelectric applications.

The $\mathrm{Ni}_{2}$ In-prototype $\mathrm{Ti}_{2} \mathrm{Si}\left(\mathrm{P}_{3} / \mathrm{mmc} 194\right)$ structure has one direct bandgap near the Fermi level, while its occupied and unoccupied bands intersect only between $L-M$ points of the first Brillouin zone; see Fig. 8. The doping of this structure may also be useful in making a direct gap semiconductor on its base.

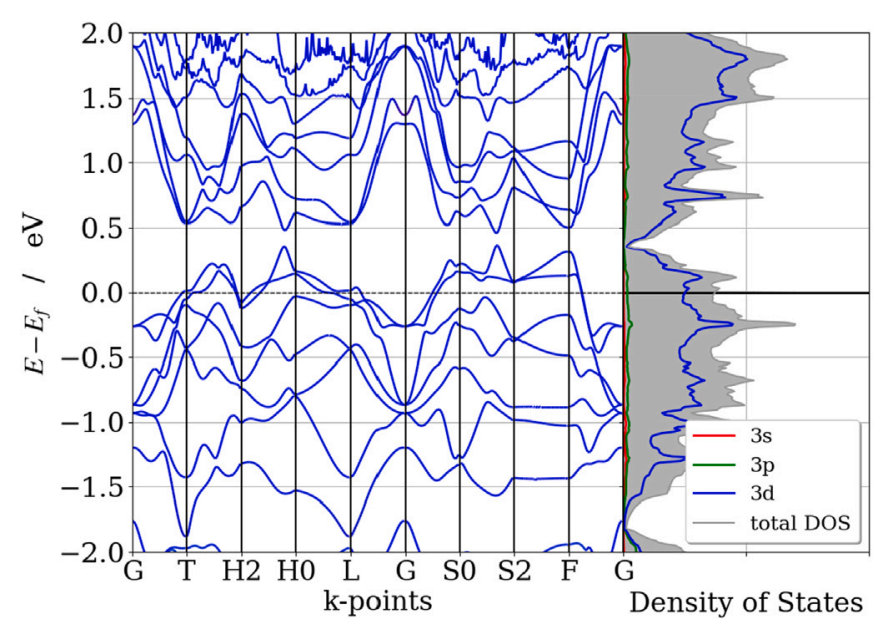

Fig. 7. Electronic band structure and density of states (elDOS) for $\mathrm{Ti}_{5} \mathrm{Si}_{2}$ ( $\mathrm{R} \overline{3} \mathrm{~m} 166$ ) structure.

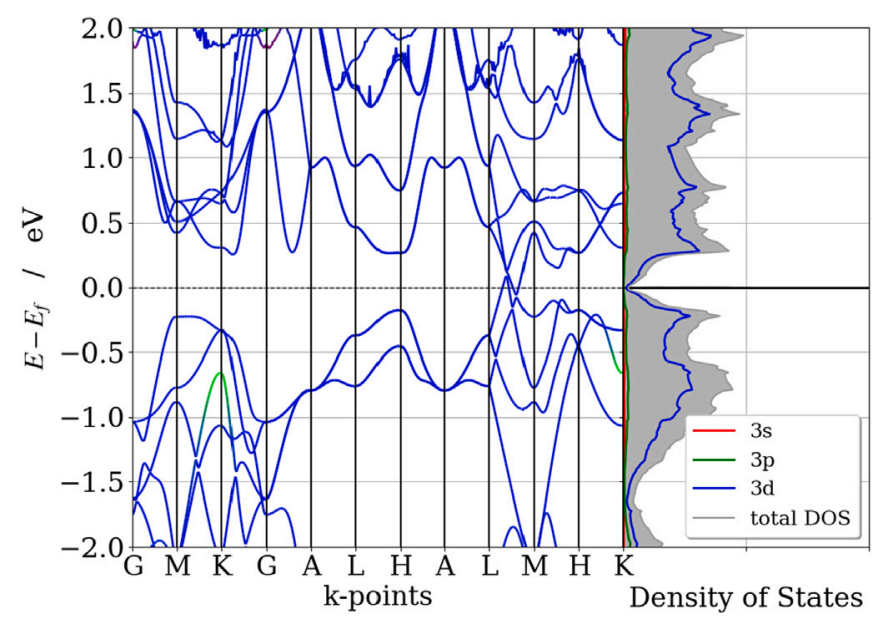

Fig. 8. Electronic band structure and density of states (elDOS) for $\mathrm{Ni}_{2} \mathrm{In}$-prototype $\mathrm{Ti}_{2} \mathrm{Si}$ $\left(\mathrm{PG}_{3} / \mathrm{mmc}\right.$ 194) structure.

\section{Conclusions}

For the first time using the evolutionary algorithm within PAW GGA calculations at zero temperatures and pressures, four variable composition searches for stable and metastable compounds in the Ti-Si system were performed. The searches predicted 1601 and 161 unique binary and unary structures, respectively. Despite the evolutionary algorithm did not found any new stable structures of silicides at $0 \mathrm{~K}$ and $0 \mathrm{GPa}$, many low-energy metastable or unstable structures were predicted.

Using the novel structure fingerprinting method, the predicted binary structures were compared with known $\mathrm{Ti}-\mathrm{Si}$ structures from databases and literature. It was found that 70 predicted binary structures excluding structures used as seeds are topologically close to one or several known structures. On the other hand, 10 low-energy structures that are known to be stable in systems of early transitional metals or rare-earth elements with $p$-elements were not predicted by the evolutionary algorithm. The later may indicate the limitations of efficiency of the evolutionary algorithms in searches for compounds in intermetallic systems with $d$-elements.

The 33 of 1601 predicted metastable and unstable binary structures with low formation energies above the convex hull and other 10 lowenergy structures from literature and databases that were not predicted by the evolutionary algorithm were additionally studied. Among the 
Table 5

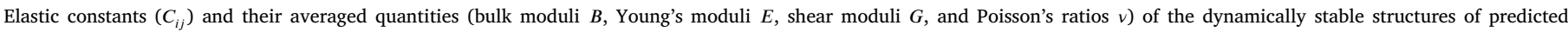

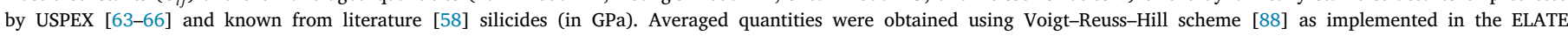

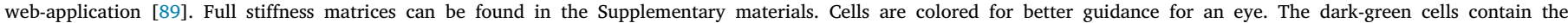
maximal values, while the white cells contain the minimal values of the corresponding quantities between the different structures.

\begin{tabular}{|c|c|c|c|c|c|c|c|c|c|c|c|c|c|c|c|c|}
\hline Comp. & Spg. & Prot. & $C_{11}$ & $C_{22}$ & $C_{33}$ & $C_{44}$ & $C_{55}$ & $C_{66}$ & $C_{12}$ & $C_{13}$ & $C_{23}$ & $B$ & $E$ & $G$ & $v$ & $B / G$ \\
\hline $\mathrm{Ti}_{13} \mathrm{Si}_{3}$ & 123 & & 163.0 & 135.0 & 148.6 & 91.6 & 89.3 & 90.4 & 101.6 & 108.1 & 111.1 & 120.4 & 130.9 & 49.6 & 0.319 & 2.426 \\
\hline $\mathrm{Ti}_{4} \mathrm{Si}$ & 2 & & 201.3 & 213.1 & 209.6 & 59.5 & 61.9 & 55.4 & 70.5 & 65.3 & 67.1 & 113.7 & 154.0 & 60.4 & 0.274 & 1.881 \\
\hline $\mathrm{Ti}_{7} \mathrm{Si}_{2}$ & 69 & & 248.9 & 222.1 & 238.7 & 97.4 & 46.0 & 68.0 & 73.1 & 57.5 & 62.1 & 121.5 & 184.5 & 74.0 & 0.247 & 1.641 \\
\hline $\mathrm{Ti}_{3} \mathrm{Si}$ & 63 & & 224.1 & 206.6 & 242.9 & 37.9 & 79.1 & 66.4 & 93.2 & 78.8 & 91.8 & 133.4 & 160.5 & 61.8 & 0.299 & 2.159 \\
\hline $\mathrm{Ti}_{3} \mathrm{Si}$ & 63 & $\mathrm{Cd}_{3} \mathrm{Y}$ & 164.9 & 205.9 & 244.9 & 37.2 & 63.4 & 94.2 & 95.0 & 96.9 & 84.4 & 128.5 & 151.4 & 58.1 & 0.304 & 2.214 \\
\hline $\mathrm{Ti}_{5} \mathrm{Si}_{2}$ & 166 & & 231.0 & 228.9 & 205.3 & 56.9 & 61.8 & 61.7 & 117.5 & 57.8 & 56.8 & 124.0 & 163.6 & 63.9 & 0.280 & 1.940 \\
\hline $\mathrm{Ti}_{2} \mathrm{Si}$ & 140 & $\mathrm{Al}_{2} \mathrm{Cu}$ & 244.2 & 244.2 & 283.5 & 95.2 & 122.2 & 122.2 & 105.1 & 80.8 & 80.8 & 145.0 & 242.8 & 99.4 & 0.221 & 1.458 \\
\hline $\mathrm{Ti}_{2} \mathrm{Si}$ & 194 & $\mathrm{Ni}_{2} \mathrm{In}$ & 284.1 & 284.1 & 296.4 & 82.1 & 82.4 & 82.4 & 119.9 & 64.9 & 64.9 & 151.3 & 223.7 & 89.2 & 0.254 & 1.696 \\
\hline $\mathrm{Ti}_{5} \mathrm{Si}_{3}$ & 140 & $\mathrm{Nb}_{5} \mathrm{Si}_{3}$ & 293.3 & 293.3 & 174.7 & 101.3 & 87.8 & 87.8 & 58.7 & 93.7 & 93.7 & 136.9 & 214.1 & 86.4 & 0.239 & 1.585 \\
\hline $\mathrm{Ti}_{5} \mathrm{Si}_{3}$ & 140 & $\mathrm{~W}_{5} \mathrm{Si}_{3}$ & 291.6 & 291.6 & 250.6 & 116.8 & 52.6 & 52.6 & 101.0 & 71.8 & 71.8 & 146.1 & 201.1 & 79.1 & 0.271 & 1.846 \\
\hline $\mathrm{Ti}_{5} \mathrm{Si}_{4}$ & 193 & $\mathrm{Ti}_{5} \mathrm{Ga}_{4}$ & 280.6 & 280.6 & 273.6 & 101.1 & 93.0 & 93.0 & 78.3 & 72.2 & 72.2 & 142.2 & 239.3 & 98.1 & 0.220 & 1.450 \\
\hline $\mathrm{Ti}_{3} \mathrm{Si}_{2}$ & 127 & $\mathrm{U}_{3} \mathrm{Si}_{2}$ & 308.9 & 308.9 & 197.3 & 103.7 & 125.5 & 125.5 & 62.1 & 94.6 & 94.6 & 144.6 & 253.0 & 104.7 & 0.208 & 1.381 \\
\hline $\mathrm{TiSi}$ & 115 & & 220.5 & 212.8 & 206.2 & 164.1 & 58.5 & 57.5 & 104.7 & 90.7 & 91.6 & 134.7 & 185.9 & 73.2 & 0.270 & 1.840 \\
\hline TiSi & 63 & $\mathrm{CrB}$ & 217.0 & 354.2 & 286.7 & 68.3 & 73.8 & 168.1 & 69.1 & 128.9 & 64.8 & 152.4 & 233.3 & 93.7 & 0.245 & 1.626 \\
\hline $\mathrm{TiSi}_{2}$ & 166 & & 181.8 & 181.8 & 279.1 & 44.3 & 124.6 & 124.6 & 93.2 & 69.6 & 69.6 & 122.0 & 188.7 & 75.9 & 0.242 & 1.606 \\
\hline $\mathrm{TiSi}_{2}$ & 180 & $\mathrm{CrSi}_{2}$ & 341.1 & 341.1 & 423.3 & 140.1 & 90.5 & 90.5 & 60.9 & 49.2 & 49.2 & 157.7 & 292.9 & 123.0 & 0.190 & 1.282 \\
\hline $\mathrm{TiSi}_{6}$ & 191 & & 224.0 & 224.0 & 217.9 & 74.7 & 73.3 & 73.3 & 74.7 & 42.4 & 42.4 & 109.2 & 188.2 & 77.6 & 0.213 & 1.407 \\
\hline
\end{tabular}

predicted low-energy structures, eight structures were found to be topologically close to the $\alpha$-Ti and were assigned to the ordered hcp superstructures representing substitutional solid solution of $\mathrm{Si}$ in $\alpha$-Ti. For the remaining 35 low-energy structures, their phonon dispersion curves were calculated. The 17 low-energy structures were found to be dynamically stable, while the remaining 18 structures were found to be dynamically unstable.

For dynamically stable structures, their mechanical properties, electronic band structures, and densities of states were calculated. It was found that all 17 dynamically stable structures are metallic and mechanically stable. The temperature dependencies of their thermodynamic stability with respect to the ground state structures on which they should decompose at $0 \mathrm{~K}$ were also assessed. The thermodynamic stability of nine structures increases with temperature, while the thermodynamic stability of eight structures decreases with temperature due to the lattice vibrations. None of the dynamically stable structures becomes thermodynamically stable at increased temperatures. Meanwhile, the question of their stabilization with pressure or the addition of other elements is still open.

The information about the predicted binary structures can be used in the development of the thermodynamic models of phases for multicomponent systems containing $\mathrm{Ti}-\mathrm{Si}$ as a subsystem, as well as for the construction and validation of the semi-empirical or machine-learning interatomic potentials for the $\mathrm{Ti}-\mathrm{Si}$ system.

\section{Declaration of competing interest}

The authors declare that they have no known competing financial interests or personal relationships that could have appeared to influence the work reported in this paper.

\section{Data availability statement}

The authors confirm that the data required to reproduce the findings of this study are available within the article and in supplementary materials and can be reproduced by any plotting and scientific visualization software and/or confirmed by DFT calculations.

\section{Acknowledgments}

The work was supported by Russian Science Foundation (Grant No. 19-73-00313).

\section{Appendix A. Supplementary data}

Supplementary material related to this article can be found online at https://doi.org/10.1016/j.calphad.2020.102201.

\section{References}

[1] L. Clevenger, R. Mann, Titanium silicides and their technological applications, MRS Proc. 320 (1993) 15.

[2] S. Parlapanska, D. Parlapanski, Corrosion behavior of mechanically alloyed Ti-Si samples, Corros. Sci. 39 (7) (1997) 1321-1327.

[3] Z. Jiang, X. Dai, H. Middleton, Effect of silicon on corrosion resistance of Ti-Si alloys, Mater. Sci. Eng. B 176 (1) (2011) 79-86.

[4] J. Xu, L. Liu, Z. Li, P. Munroe, Z.-H. Xie, Niobium addition enhancing the corrosion resistance of nanocrystalline Ti5Si3 coating in H2SO4 solution, Acta Mater. 63 (2014) 245-260.

[5] T. Kitashima, Y. Yamabe-Mitarai, Oxidation behavior of germanium- and/or silicon-bearing near- $\alpha$ titanium alloys in air, Metall. Mater. Trans. A 46 (6) (2015) 2758-2767.

[6] M. Satou, K. Abe, H. Kayano, Tensile properties and microstructures of neutron irradiated V-Ti-Cr-Si type alloys, J. Nucl. Mater. 212-215 (PART 1) (1994) 794-798.

[7] D. Xiangfeng, Y. Huang, H. Zhang, X. Zhong, High energy density silicide-air batteries, 2016, p. 11.

[8] Z. Liu, P.B. Balbuena, P.P. Mukherjee, Mesoscale evaluation of titanium silicide monolayer as a cathode host material in lithium-sulfur batteries, JOM 69 (9) (2017) 1532-1536.

[9] D. Handtrack, F. Despang, C. Sauer, B. Kieback, N. Reinfried, Y. Grin, Fabrication of ultra-fine grained and dispersion-strengthened titanium materials by spark plasma sintering, Mater. Sci. Eng. A 437 (2) (2006) 423-429.

[10] D. Handtrack, C. Sauer, B. Kieback, Microstructure and properties of ultrafinegrained and dispersion-strengthened titanium materials for implants, J. Mater. Sci. 43 (2) (2007) 671-679.

[11] L. Kaufman, Coupled phase diagrams and Thermochemical data for transition metal binary systems-VI, CALPHAD 3 (1) (1979) 45-76.

[12] C. Vahlas, P. Chevalier, E. Blanquet, A thermodynamic evaluation of four Si-M ( $\mathrm{M}=$ Mo, Ta, Ti, W) binary systems, CALPHAD 13 (3) (1989) 273-292.

[13] H. Seifert, H. Lukas, G. Petzow, Thermodynamic optimization of the ti-si system, Zeitschrift fuer Metallkunde 87 (1) (1996) 2-13.

[14] Y. Du, J. Schuster, A reinvestigation of the constitution of the partial system TiSi-Si, J. Mater. Sci. Lett. 7 (16) (1998) 1407-1408.

[15] A. Kostov, D. Zivkovic, B. Friedrich, Thermodynamic predicting of Si-Me (Me = Ti, Al) binary systems, J. Min. Metall. Sect. B: Metallurgy 43 (1) (2007) 29-38.

[16] M. Fiore, F.B. Neto, C.R. Azevedo, Assessment of the Ti-Rich corner of the Ti-Si phase diagram: The recent dispute about the eutectoid reaction, Mater. Res. 19 (4) (2016) 942-953.

[17] F.-Y. Hsu, G.-X. Wang, H.-J. Klaar, Orientation relationships between silicides and other phases in a Ti-45at.\%Al-2.7at.\%Si alloy, Scr. Metall. Mater. 33 (4) (1995) 597-601.

[18] C.G. Rhodes, A.K. Ghosh, R.A. Spurling, Ti-6Al-4V-2Ni as a matrix material for a SiC-reinforced composite, Metall. Trans A 18 (12) (1987) 2151-2156.

[19] J. Schneibel, C. Rawn, Thermal expansion anisotropy of ternary titanium silicides based on ti5si3, Acta Mater. 52 (13) (2004) 3843-3848. 
[20] C. Yeh, H. Wang, W. Chen, A comparative study on combustion synthesis of Ti-Si compounds, J. Alloys Compd. 450 (1-2) (2008) 200-207.

[21] A. Madsen, H. Ghonem, Separating the effects of Ti3Al and silicide precipitates on the tensile and crack growth behavior at room temperature and $593^{\circ} \mathrm{C}$ in a near-alpha titanium alloy, J. Mater. Eng. Perform. 4 (3) (1995) 301-307.

[22] N.E. Paton, M.W. Mahoney, Creep of titanium-silicon alloys, Metall. Trans. A 7 (11) (1976) 1685-1694.

[23] P.S. Kotval, R.W. Calder, In situ identification of the silicide phase in super- $\alpha$ titanium alloys, Metall. Trans. 3 (5) (1972) 1308-1311.

[24] K. Lee, J.T. Lue, Formation of titanium silicides and their refractive index measurements, Phys. Lett. A 125 (5) (1987) 271-275.

[25] S. Agarwal, E.J. Cotts, S. Zarembo, R. Kematick, C. Myers, The heat capacities of titanium silicides Ti5Si3, TiSi and TiSi2, J. Alloys Compd. 314 (1-2) (2001) 99-102.

[26] G. Ottaviani, C. Nobili, Silicide formation, Thin Solid Films 163 (1988) 111-121.

[27] B. Fu, H. Wang, C. Zou, Z. Wei, The influence of Zr content on microstructure and precipitation of silicide in as-cast near $\alpha$ titanium alloys, Mater. Charact. 99 (2015) $17-24$.

[28] Y. Zhan, X. Zhang, J. Hu, Q. Guo, Y. Du, Evolution of the microstructure and hardness of the Ti-Si alloys during high temperature heat-treatment, J. Alloys Compd. 479 (1-2) (2009) 246-251.

[29] C. Ramachandra, V. Singh, Sllicide phases in some complex titanium alloys, Metall. Trans. A 23 (2) (1992) 689-690.

[30] A. Woodfield, P. Postans, M. Loretto, R. Smallman, The effect of long-term high temperature exposure on the structure and properties of the titanium alloy $\mathrm{Ti}$ 5331S, Acta Metall. 36 (3) (1988) 507-515.

[31] A.S. Ramos, C.A. Nunes, G.C. Coelho, On the peritectoid Ti3Si formation in Ti-Si alloys, Mater. Charact. 56 (2) (2006) 107-111.

[32] X. Wang, M. Jahazi, S. Yue, Investigation of $\alpha$ platelet boundaries in a near- $\alpha$ titanium alloy, Mater. Sci. Eng. A 492 (1-2) (2008) 450-454.

[33] F. Sun, J. Li, H. Kou, B. Tang, J. Cai, Nano-precipitation and tensile properties of Ti60 alloy after exposure at $550^{\circ} \mathrm{C}$ and $650^{\circ} \mathrm{C}$, Mater. Sci. Eng. A 626 (2015) 247-253.

[34] R.G. Nichols, H.M. Flower, D.R.F. West, The effect of an addition of molybdenum on the quenched and aged structure of a Ti-1 wt \% Si alloy, J. Mater. Sci. 8 (2) (1973) 261-264.

[35] S. Chambers, D. Hill, F. Xu, J. Weaver, Silicide formation at the Ti/Si(111) interface: Diffusion parameters and behavior at elevated temperatures, Phys. Rev. B 35 (2) (1987) 634-640.

[36] Z. Zhang, H.M. Flower, Composition and lattice parameters of silicide and matrix in cast Ti-Si-Al-Zr alloys, Mater. Sci. Technol. 7 (9) (1991) 812-817.

[37] S.M. Tuominen, G.W. Franti, D.A. Koss, The influence of Si on precipitation phenomena and age hardening of a beta Ti alloy, Metall. Trans. A 8 (3) (1977) $457-463$.

[38] R. Yu, L. He, J. Guo, H. Ye, V. Lupinc, Orientation relationship and interfacial structure between $\zeta$-Ti5Si3 precipitates and $\gamma$-TiAl intermetallics, Acta Mater. 48 (14) (2000) 3701-3710.

[39] B.P. Bewlay, M.R. Jackson, R.R. Bishop, The Nb-Ti-Si ternary phase diagram: Determination of solid-state phase equilibria in Nb- and Ti-rich alloys, J. Phase Equilib. 19 (6) (1998) 577-586.

[40] A. Madsen, E. Andrieu, H. Ghonem, Microstructural changes during aging of a near- $\alpha$ titanium alloy, Mater. Sci. Eng. A 171 (1-2) (1993) 191-197.

[41] J.K. Tien, J.C. Chesnutt, D.E. Peacock, Thermomechanical manipulation of precipitate shape in a titanium-base alloy, Metall. Trans. 3 (9) (1972) 2542-2544.

[42] H.M. Flower, P.R. Swann, D.R.F. West, Silicide precipitation in the Ti-Zr-Al-Si system, Metall. Mater. Trans. B 2 (12) (1971) 3289-3297.

[43] C. Ramachandra, V. Singh, Silicide precipitation in alloy Ti-6AI-5Zr-0.5Mo0.25Si, Metall. Trans. A 13 (5) (1982) 771-775.

[44] J.-M. Oh, J.-W. Lim, B.-G. Lee, C.-Y. Suh, S.-W. Cho, S.-W. Lee, G.-S. Choi, Grain refinement and hardness increase of titanium via trace element addition, Mater. Trans. 51 (11) (2010) 2009-2012.

[45] L. Chumbley, B. Muddle, H. Fraser, The crystallography of the precipitation of Ti5Si3 in Ti-Si alloys, Acta Metall. 36 (2) (1988) 299-310.

[46] Y. Imbert, Creep resistance and embrittlement of a Ti-6\%Al-5\%Zr-1\%W-0.4\% Si alloy, J. Less Common Metals 37 (1) (1974) 71-89.

[47] S. Kirklin, J.E. Saal, V.I. Hegde, C. Wolverton, High-throughput computational search for strengthening precipitates in alloys, Acta Mater. 102 (2016) 125-135.

[48] N.H. Salpadoru, H.M. Flower, Phase equilibria and transformations in a Ti-Zr-Si system, Metall. Mater. Trans. A 26 (2) (1995) 243-257.

[49] M. Hansen, H. Kessler, D. McPherson, The titanium-silicon system, Trans. Am. Soc. Met. 44 (1952) 518-538.

[50] V. Svechnikov, Y. Kocherzhisky, L. Yupko, O. Kulik, E. Shishkin, Phase diagram of the titanium-silicon system, Dokl. Akad. Nauk SSSR 193 (2) (1970) 393-396.

[51] W. Wakelkamp, F. van Loo, R. Metselaar, Phase relations in the Ti-Si-C system, J. Eur. Ceram. Soc. 8 (3) (1991) 135-139.

[52] H. Tu, Q. Zhao, Y. Liu, J. Wang, X. Su, S. Liu, The $450^{\circ} \mathrm{C}$ and $600^{\circ} \mathrm{C}$ isothermal sections of the Zn-Ti-Si system, J. Alloys Compd. 616 (2014) 594-600.

[53] M. Bulanova, L. Tretyachenko, M. Golovkova, K. Meleshevich, Phase equilibria in the $\alpha$-Ti-Al-Si region of the Ti-Si-Al system, J. Phase Equilibria Diffusion 25 (3) (2004) 209-229.
[54] D. Robins, I. Jenkins, The heats of formation of some transition metal silicides, Acta Metall. 3 (6) (1955) 598-604.

[55] H. Niu, X.Q. Chen, W. Ren, Q. Zhu, A.R. Oganov, D. Li, Y. Li, Variablecomposition structural optimization and experimental verification of MnB3 and MnB4, Phys. Chem. Chem. Phys. 16 (30) (2014) 15866-15873.

[56] Q. Wu, J.-J. Zhang, P. Hao, Z. Ji, S. Dong, C. Ling, Q. Chen, J. Wang, Versatile titanium silicide monolayers with prominent ferromagnetic, catalytic, and superconducting properties: Theoretical prediction, J. Phys. Chem. Lett. 7 (19) (2016) 3723-3729.

[57] Y. Wang, J. Lv, L. Zhu, Y. Ma, Crystal structure prediction via particle-swarm optimization, Phys. Rev. B 82 (9) (2010) 094116

[58] C. Colinet, J.-C. Tedenac, Structural stability of intermetallic phases in the Si-Ti system. point defects and chemical potentials in D88-Si3Ti5 phase, Intermetallics 18 (8) (2010) 1444-1454.

[59] A. Jain, S.P. Ong, G. Hautier, W. Chen, W.D. Richards, S. Dacek, S. Cholia, D. Gunter, D. Skinner, G. Ceder, K.a. Persson, Commentary: The materials project: A materials genome approach to accelerating materials innovation, APL Mater. 1 (1) (2013) 011002.

[60] J.E. Saal, S. Kirklin, M. Aykol, B. Meredig, C. Wolverton, Materials design and discovery with high-throughput density functional theory: The open quantum materials database (OQMD), JOM 65 (11) (2013) 1501-1509.

[61] S. Kirklin, J.E. Saal, B. Meredig, A. Thompson, J.W. Doak, M. Aykol, S. Rühl, C. Wolverton, The open quantum materials database (OQMD): assessing the accuracy of DFT formation energies, npj Comput. Mater. 1 (1) (2015) 15010.

[62] C. Oses, E. Gossett, D. Hicks, F. Rose, M.J. Mehl, E. Perim, I. Takeuchi, S. Sanvito, M. Scheffler, Y. Lederer, O. Levy, C. Toher, S. Curtarolo, AFLOW-CHULL: Cloudoriented platform for autonomous phase stability analysis, J. Chem. Inf. Model. 58 (12) (2018) 2477-2490.

[63] C.W. Glass, A.R. Oganov, N. Hansen, USPEX-EVolutionary crystal structure prediction, Comput. Phys. Comm. 175 (11-12) (2006) 713-720.

[64] A.R. Oganov, C.W. Glass, Crystal structure prediction using ab initio evolutionary techniques: Principles and applications, J. Chem. Phys. 124 (24) (2006) 244704.

[65] a.R. Oganov, Y. Ma, a.O. Lyakhov, M. Valle, C. Gatti, Evolutionary crystal structure prediction as a method for the discovery of minerals and materials, Rev. Mineral. Geochem. 71 (1) (2010) 271-298.

[66] A.O. Lyakhov, A.R. Oganov, H.T. Stokes, Q. Zhu, New developments in evolutionary structure prediction algorithm USPEX, Comput. Phys. Comm. 184 (4) (2013) 1172-1182.

[67] G. Kresse, J. Furthmüller, Efficiency of ab-initio total energy calculations for metals and semiconductors using a plane-wave basis set, Comput. Mater. Sci. 6 (1) (1996) 15-50.

[68] G. Kresse, Efficient iterative schemes for ab initio total-energy calculations using a plane-wave basis set, Phys. Rev. B 54 (16) (1996) 11169-11186.

[69] A.R. Oganov, Modern Methods of Crystal Structure Prediction, Wiley-VCH Verlag GmbH \& Co. KGaA, Weinheim, Germany, 2010,

[70] A.R. Oganov, A.O. Lyakhov, M. Valle, How evolutionary crystal structure prediction works-and why, Acc. Chem. Res. 44 (3) (2011) 227-237.

[71] P.V. Bushlanov, V.A. Blatov, A.R. Oganov, Topology-based crystal structure generator, Comput. Phys. Comm. 236 (2019) 1-7.

[72] A. Kartamyshev, D. Poletaev, A. Lipnitskii, The influence of lattice vibrations and electronic free energy on phase stability of titanium silicides and si solubility in hcp titanium: A DFT study, CALPHAD 65 (February) (2019) 194-203.

[73] A.R. Oganov, M. Valle, How to quantify energy landscapes of solids, J. Chem. Phys. 130 (10) (2009) 104504.

[74] M. Valle, A.R. Oganov, Crystal fingerprint space - a novel paradigm for studying crystal-structure sets, Acta Crystallogr. Sect. A 66 (5) (2010) 507-517.

[75] R.J. Kematick, C.E. Myers, Thermodynamics of the phase formation of the titanium silicides, Chem. Mater. 8 (1) (1996) 287-291.

[76] S. Meschel, O. Kleppa, Standard enthalpies of formation of some 3d transition metal silicides by high temperature direct synthesis calorimetry, J. Alloys Compd. 267 (1-2) (1998) 128-135.

[77] I. Ansara, A.T. Dinsdale, M.H. Rand, COST 507, Definition of Thermochemical and Thermophysical Properties to Provide a Database for the Development of New Light Alloys: Thermochemical Database for Light Metal Alloys - Vol. 2, Office for Official Publications of the European Communities, 1998, p. 396.

[78] S. Fries, T. Jantzen, Compilation of CALPHAD'formation enthalpy data: Binary intermetallic compounds in the COST 507 Gibbsian database, Thermochimica acta 314 (1998).

[79] J.P. Perdew, K. Burke, M. Ernzerhof, Generalized gradient approximation made simple, Phys. Rev. Lett. 77 (18) (1996) 3865-3868.

[80] P.E. Blöchl, Projector augmented-wave method, Phys. Rev. B 50 (24) (1994) 17953-17979.

[81] M. Methfessel, A. Paxton, High-precision sampling for Brillouin-zone integration in metals, Phys. Rev. B 40 (6) (1989) 3616-3621.

[82] D.A. Aksyonov, S.S. Fedotov, K.J. Stevenson, A. Zhugayevych, Understanding migration barriers for monovalent ion insertion in transition metal oxide and phosphate based cathode materials: A DFT study, Comput. Mater. Sci. 154 (May) (2018) 449-458

[83] N.E.R. Zimmermann, A. Jain, Local structure order parameters and site fingerprints for quantification of coordination environment and crystal structure similarity, RSC Adv. 10 (10) (2020) 6063-6081. 
[84] A. Togo, F. Oba, I. Tanaka, First-principles calculations of the ferroelastic transition between rutile-type and $\mathrm{CaCl} 2$-type $\mathrm{SiO} 2$ at high pressures, Phys. Rev. B 78 (13) (2008) 134106.

[85] E. Fisher, C. Renken, Single-crystal elastic moduli and the hcp $\rightarrow$ bcc transformation in Ti, Zr, and Hf, Phys. Rev. 135 (2A) (1964) A482-A494.

[86] J. Hall, Electronic effects in the elastic constants of n-type silicon, Phys. Rev. 161 (3) (1967) 756-761.

[87] K. Kishida, M. Fujiwara, H. Adachi, K. Tanaka, H. Inui, Plastic deformation of single crystals of Ti5Si3 with the hexagonal d88 structure, Acta Mater. 58 (3) (2010) 846-857.

[88] R. Hill, The elastic behaviour of a crystalline aggregate, Proc. Phys. Soc. A 65 (5) (1952) 349-354.
[89] R. Gaillac, P. Pullumbi, F.-X. Coudert, ELATE: An open-source online application for analysis and visualization of elastic tensors, J. Phys.: Condens. Matter 28 (27) (2016) 275201.

[90] S. Curtarolo, W. Setyawan, S. Wang, J. Xue, K. Yang, R.H. Taylor, L.J. Nelson, G.L. Hart, S. Sanvito, M. Buongiorno-Nardelli, N. Mingo, O. Levy, Aflowlib.org: A distributed materials properties repository from high-throughput ab initio calculations, Comput. Mater. Sci. 58 (2012) 227-235.

[91] A.M. Ganose, A. Jain, Robocrystallographer: Automated crystal structure text descriptions and analysis, MRS Commun. 9 (3) (2019) 874-881.

[92] C. Colinet, J.-C. Tedenac, First-principles calculations of phase stability in the Ti-Zr-Si ternary system, CALPHAD 37 (2012) 94-99.

[93] S. Pugh, XcII. Relations between the elastic moduli and the plastic properties of polycrystalline pure metals, Lond. Edinb. Dublin Philos. Mag. J. Sci. 45 (367) (1954) 823-843. 